\title{
Visibility of development stories in selected religious media discourse
}

\author{
Negesse Gessese (10 ${ }^{1 凶}$, Amanuel Gebru ${ }^{1} \&$ Biset Nigatu ${ }^{1}$
}

This study explores patterns in the portrayal of development issues in the religious media from 1993 to 2021, in an attempt to illustrate the existence of hierarchical representations of development issues using sources, actors, and dominant frames. To this end, we use a quantitative method that considers the development content of two Ethiopian religious magazines: Hamer and Hintset. Our results reveal that across the selected years, the two magazines together presented 685 articles on development (359 the Hamer and 326 in Hintset). We employ data analysis using SPSS software, in which both descriptive and inferential statistical techniques were utilized for data presentation. We determine that political, economic, and natural resource development issues are the most scarcely covered issues as compared to social, moral, peace themes. Economic (chi-square $=5.122, p=0.024$, and $p<0.05$ ), social development issues (chi-square $=6.207, p=0.018$, and $p<0.05$ ) have a relationship with the year of publication in Hintset. Adherents, believers at the grassroots level, were the most frequent sources and story actors in the magazines. This shows participatory development communication was employed in the mediatization of development issues. The frame of development issues did not have a relationship with the year of publication. Finally, Hamer and Hintset included significant coverage of development issues, although development priorities are different. Hamer covered more social development issues whereas Hintset covered more moral development issues. In summary, our findings reveal that the religious media's representation of development (685 articles, 38.8\%) is at a high level in Ethiopia. We, therefore, suggest that local and global development agencies should work with faith-based media as development partners.

\footnotetext{
${ }^{1}$ Bahir Dar University, Bahir Dar, Ethiopia. ${ }^{凶}$ email: negessenegesse@gmail.com
} 


\section{Introduction}

- his $^{1}$ article focuses on highlighting the coverage of development efforts in the contemporary religious media in Ethiopia, one of the most religious countries in Africa. Moreover, it questions the Ethiopian religious media in line with communication for development paradigms. The aim is to examine the deliberation of the coverage of development issues in the Ethiopian religious media with a modified, transformed vitality that plays an active role and influences Ethiopian society both socially and spiritually. We also provide an analysis of the degree to which the current religious media situation influences the political, economic, social, historical, moral, and cultural landscape. By exclusively focusing on the case of the Ethiopian Orthodox Tewahedo Church (EOTC), and the Ethiopian Evangelical Church (EEC), this paper sheds some light on the extent of the religious media is serving as an alternative development platform for communities.

The interrelationship between religious media and development is a theme that attracted less attention of scholars across various disciplines around the globe in general and in subSaharan African countries in particular. Accordingly, there is little research in Ethiopia addressing the coverage of development issues in religious media prospects. While numerous other studies have been undertaken to assess newspaper content in terms of development, this component of the research is distinguished, firstly, by its focus on the two magazines involved in the study, secondly, the comparison and contrast between them and, thirdly, an attempt to quantifying the relationship between the source, story actors, dominant frames in line with the years of publication with the diverse manifestations of development constructs in the magazines.

The paper is structured into six sections. The first section presents an introduction to this article. The second part deals with a brief background on the religious media landscape in Ethiopia. The third section gives readers a brief overview of the EOTC and EEC contemporary developments in the use of print media, Hamer and Hintset magazines. The fourth section presents and analyses the coverage of development issues in the selected magazines. The fifth section presents the discussion of results in line with other scholarly works. The final section presents a concluding remark.

Background. The current demographic distribution of religion in Ethiopia is much different from 100 years ago. A century ago, Ethiopia was a Christian nation, Ethiopian Orthodox nation. The majority of the people belonged to the EOTC. However, now things have changed. Muslims have a significant share in the population to the point claiming to be the majority although the census shows that Christianity is the dominant one.

Especially, the last 50 years have shown a radical shift in the distribution of the Christian sects across the country. The Protestants/Evangelicals have grown to have voices and have become the fastest-growing religious group in the country. This has created tensions between EOTC and the growing protestant churches. The reasons for the dramatic surge of Protestantism in Ethiopia are many, which include the escalation of indigenous reformation taking place in the EOTC and ECC, vast missionary endeavors, contextualized (to the language and culture of the people of different ethnic groups in the country) preaching and Bible translations.

The Ethiopian religious media have also developed not only to transmit and communicate faith but also to control the communication of religious and secular information. Religious media encourage confessions (especially the Evangelical Church) to become not only social and cultural partners of the state but political partners. The Ethiopian Orthodox Tewahedo Church which had been the dominant religious denomination is the historical partner of the state in spiritual, cultural and political matters, and it proclaims itself the guarantor of national identity. However, the general tendency of studies on religious vitality is to argue that former communist countries (like Ethiopia) are exposed to premature secularization (Pickel, 2012; Norris and Inglehart, 2014).

Religious media and coverage of development were the two main concepts of this study. The term development refers to a multidimensional process involving major changes in social structures, popular attitudes, and national institutions as well as the acceleration of economic growth, the reduction of inequality, and the eradication of absolute poverty (Todaro and Smith, 2009). This is because development is not solely about economic or technological growth, but it is also importantly about increases in knowledge and skills, growth of new awareness, enhancing the human soul, and the combination of human certainty (Servaes, 1999).

The concept of development has been in constant flux due to changes in society and its passing through various stages of development itself (So, 1990). Because of globalization and its ensuing changes in cultural texture, economy, polity, innovation, and communication viewpoints, the indicators of development are likewise changing, as per the requirements of the particular society (Narula and Duysters, 2004). It is a broadly participatory cycle of coordinated social change in the public arena, expected to achieve social and material for most individuals through their dealing with their condition (Singhal and Rogers, 2001). Similarly, Fisher (2011) looks at development as the material and spiritual quality of human life.

Therefore, though observed from alternate points of view, improvement implies one fundamental thing in all viewpoints and to all individuals - an improvement in the human, social, financial, and political states of the individual and subsequently of the public. It is not exclusively a matter of innovation or gross public item; more critically, it involves expanded information and abilities, development of new awareness, expansion of the human mind, uplifting the human spirit, and the fusion of human confidence (Burkey, 1993).

The failure and success of most development projects are often determined by two crucial factors, that is, communication and people's involvement (Mefalopulos, 2008). A great deal of scholarly analysis has addressed how the development would qualify to worldwide democratic communication. Alternately, numerous modern correspondence media were, in themselves, viewed as markers of development communication, and advancement has been seen as a firmly interwoven marvel where one is accepted to ensure the other (Gumucio-Dagron, 2001). This thought unmistakably features the part of development communication and media in accomplishing proposed development objectives. The media in general helps create awareness for development and its possible approach by disseminating information to the society down to the root level.

The mass media are also agents of social change in the service of national development (So, 1990). The change in behavior expected after interacting with media should include changes in attitudes, beliefs, skills, and social norms (Moyer-Gusé, 2008). However, the media can also provoke suspicion, fear, discrimination, and violence by strengthening stereotypes, fostering intergroup tension, and excluding certain groups from public discourse (International Program for the Development of Communication, 2008).

Media are powerful drives for socio-economic transformation in developing countries such as Ethiopia as the country is in 
critical development problems, one expects the media to supplement and encourage the process of producing informed citizens. To do so, the Transitional Government of Ethiopia (TGE) in 1992 (article 4:1) stated that the press stands for the pursuit of fundamental freedom, peace, democracy, justice, equality, and for the acceleration of social and economic development. It continues to provide the people with information critical for making enlightened decisions and choices on socioeconomic issues. Its role in nation-building is often linked to a role in promoting socio-economic development on the basis that without national unity it is not possible to mobilize society for national development (Chala, 2012).

In Ethiopia, there has been an obvious gap between the government possessed and private press: more often the government press introduced an image of homogeneity with almost no proof of investigative, critical, or even middle original journalistic activity, while the private press acted as a host of highly variable quality (Amanuel, 2004). Similarly, Moges (2007) conducted the extent of the coverage of development issues on Ethiopian Radio news. He examined the priority Radio Ethiopia gives to development issues. The findings revealed that Ethiopian Radio as an agenda-setter was rather weak. Rural development news items got rather little coverage and occurrence distribution during the selected period.

Chala (2012) studied the coverage of development issues in government and private newspapers in Ethiopia. The finding revealed that private media covered fewer development issues than government media. The financial advancement was viewed as the most significant part of improvement inclusion in the studied newspapers. Chala (2012) concluded that the Ethiopian press, particularly the government-owned one, gave little coverage of the country's social, economic, and political issues.

This research filled a gap in covering development issues between private and government media in Ethiopia. Government media gave less emphasis to development activities than to others issues, political, for the progress of the country. Whereas private media gave more emphasis to sensational issues and only pay attention to development issues when they represent failures. So, the researchers inquired to know if religious media played a middle ground for the visibility of development issues in Ethiopia.

Hence, this study aims to examine the coverage, source, story actors, and dominant frames of development contents of Christian print media (Ethiopian Orthodox Tewahedo Church, Hamer magazine, and Ethiopian Evangelical Church, Hintset) and their relationship in Ethiopia from 1993 to 2021. Therefore, the following research questions are posed.

1. To what extent has the issue of development been central to EOTC-Hamer and EEC- Hintset in Ethiopia?

2. What are the differences/ similarities between the development content priorities, dominant sources, story actors, and dominant frames of Hamer and Hintset magazines during different periods of publications in Ethiopia?

Theoretical framework. The media are as much influenced by society as society is influenced by the media, and the impact is mutual and continuous (Vilanilam, 2005). Hence, religious organizations devote considerable resources to communication and education designed to show their beliefs and principles to their adherents and to take care of the salience of these beliefs and principles within the daily lives of their followers and even within the lives of a more general population (Rashi and McCombs, 2015).

Agenda setting. A useful intellectual tool for describing and analyzing these communication efforts is agenda-setting theory, which examines the connection between the content of the messages distributed by the mass media (McCombs et al., 2014). Agenda-setting theory asserts the existence of a serious link between the prominence given to topics in a very communicator's messages and their perceived importance within the prominence. Topics emphasized within the mass media or other channels are viewed as being more important than those not covered (McCombs and Shaw, 1993). Moreover, the extent of the coverage itself serves to render a selected topic more significant than one that has not been the topic of major media attention. In short, there is no single rule to say this or that issue must be given priority, as different media have their agendas.

Agenda-setting theory examines an earlier outcome within the hierarchy of media effects to see those topics that are considered the foremost powerful and merit attention (Watson, 2008). Our specific focus herein is on the religious media agenda, which has committed itself to creating Christianity and development issues accessible to adherents in every corner of the country and to influence public discourse.

An agenda, first, consists of a collection of topics communicated in a hierarchy at a given point in time. The agenda may be put in a hierarchy because the included topics do not all bear identical weight (Rogers et al., 1993). Some receive considerable attention, others much less. An agenda presented by mass media is compared with the agenda of those same topics created by members of the public, and considerable research has documented that the media agenda contains a substantive impact on the public agenda (Zhou et al., 2016). In other words, the media frequently have strong agenda-setting effects on the public.

The more repeated issues are likely the media agenda would be. As development media theory began from the agenda-setting theory espoused by (McCombs and Shaw, 1972), which stated that the media tell us not what to think but what to think about, Agenda-setting theory (first and second-level) is used as one of the theories of this research.

Second-level agenda setting (framing theory). The theoretical foundations that enabled the birth and development of the theory of framing are located in interpretive sociology, which considers that people's interpretation of reality and everyday life depends fundamentally on interaction and the definition of situations. This definition of the situation is mediated by intersubjective processes. In other words, people's approach to reality takes into account the contributions of others. The performance of people would be determined by this interpretation, and that is why the definition of the situation is linked with action and interaction (Sádaba-Garraza, 2001).

Despite these sociological foundations, Gregory Bateson (1972) used the term frame with the current sensor for the first time in an essay on the psychology of perception. Bateson pointed out that frame is a psychological concept, but refers to the importance of messages as elements that condition their construction and definition: "Any message, which either explicitly or implicitly, defines a frame gives the receiver instructions or aids in his attempt to understand the messages included within the frame" (Bateson, 1972: p. 188).

Bateson defines the concept of the frame by using two analogies: a picture frame and Venn diagrams, which are used in mathematical set theory. For Bateson, frame, as the diagram that includes the elements of a mathematical set, has a double function: to include elements within its borders and exclude those that are outside it. Like a picture frame, a frame tries to organize people's perception, by urging people to attend to what is within it and to ignore what is outside it. This approach to the frame was so successful that Tuchman (1978), would use the picture frame analogy to explain the concept. 
This is very similar to the subsequent definition offered by Gitlin (1980), who argues that a frame is built through selection, emphasis, and exclusion. A particular frame makes people focus their attention on some messages) and to ignore some other messages. Bateson's frames provide a set of keys to interpret reality, in the same way that the picture frame indicates its viewers to translate what is inside it, they cannot apply the same sort of thinking they apply to translate what is outside it. In the analogy of set theory, messages enclosed in a single diagram share common features that provide clues to interpret them.

The frame facilitates the understanding of the messages it contains, by reminding viewers that the messages placed inside it are relevant and are connected in some way and that those messages that are outside it must be ignored. This is a metacommunicative use of language, which allows the contextualization of the messages that will be perceived, and with the particularity that the vast majority of meta-communicative messages remain implicit, which will generate some operating problems in the empirical detection of frames.

The theoretical body of framing started to be developed from the 1970s, initially by the hands of cognitive psychology. The concept and theories of framing were recovered for the field of sociology by Erving Goffman (1974), and it was this renewed sociological perspective that was used in communication studies. Goffman refers to a frame as a social framework and as a mental schema that allows users to organize experiences.

The original meaning of frame expanded from the individual to the collective, from the psychological to the sociological realm, because for Goffman, frames are instruments of society that allow people to maintain a shared interpretation of reality. This expansion of the concept of the frame became useful for the study of journalistic messages, when it was considered that the media have a great capacity to generate and modify the social frameworks of interpretation, by intervening in the creation of a shared social discourse.

\section{Research method}

Quantitative research is conducted in the tradition of the natural sciences. Therefore, its approach to the study of reality is structured, measured, and, to a large extent, replicable. Such measurement facilitates adequacy, consistency, uniformity, comparison, accuracy, and precision in describing and assessing concepts (Sarantakos, 2005). Moreover, it offers researchers the opportunity to govern causal relationships in wider social contexts (Bryman, 2006).

Sarantakos (2005) defines content analysis as a documentary method that aims at a quantitative and/or qualitative analysis of the content of texts, pictures, films, and other forms of verbal, visual, or written communication. According to Weber (2009), this research method uses a set of procedures to make valid inferences from such texts. Therefore, content analysis is about making valid inferences from the content of media texts in a quantitative manner.

Content analysis usually yields unobtrusive measures, in which neither the sender nor the receiver of the message is aware that it is being analyzed. Hence, there is little danger that the act of measurement itself will act as a force for change that confounds the data (Weber, 2009). Sarantakos (2005) also states the method is non-reactive, transparent, unobtrusive, and what is perhaps most relevant to this study.

Research setting. Ethiopia is the third-largest Christian population in sub-Saharan Africa, next to Nigeria and the Democratic Republic of the Congo (Sahgal and Smith, 2009). It has had a big Christian presence since the establishment of the Ethiopian
Orthodox Church in the early 4 th century. Since that point, the Orthodox Church has remained Ethiopia's most influential religious body, with strong links between church, state, and national identity. The country's Christians signify about $63 \%$ of the population. Ethiopia's Christian community traces back to the 4th century when the emperor of the Ethiopian Axumite Kingdom converted to Christianity. After the emperor's conversion, the patriarch of Alexandria in Egypt appointed a bishop to oversee a replacement church in Ethiopia.

The Ethiopian Orthodox Tewahedo Church which is one of the world's oldest churches has its liturgical, language and calendar. The overwhelming majority of Ethiopia's Christians have adhered to the Ethiopian Orthodox Church for many of the past 1700 years (Sahgai and Smith, 2009). Ethiopian Orthodox Tewahedo Church Sunday school of saints' media department began producing "Hamer" magazine in May 1993 as one of the missions that have been given to the holy church is to transfer the word of God in a special way to the Christian people.

Ethiopian Evangelical Church established its evangelical service long ago. Recently, it has reached its adherents through print and online media. Hintset magazine was launched in 2014 by Hintset Christian Society, which is a faith-based society founded in 2013 by a group of Christians who are committed to the expansion and edification of the Evangelical Churches of Ethiopia. The Ge'ez word "Hintset", which means "to edify" or "to build", is intended to describe this commitment. Hintset Christian Society seeks to foster Biblical knowledge and Christian values to equip Ethiopian Evangelical Christians to fulfill the Gospel mandate. It is there to fill the gaps that the Ethiopian Evangelical community faces in its pursuit of fulfilling the great commission in Ethiopia and beyond, by contributing positively in seizing its opportunities and overcoming the challenges, in a way that is Biblical and reflective of Christian ethics. The editor-in-chief at the time of research has been Mikiyas Belay. The magazine was found in print, but now it is only on their website due to the rise of publication costs.

Sampling techniques and sample. Sarantakos (2005) states that sampling decisions have to be made on the selection of the medium, selection of the date of publication, and the selection of the parts of the medium to be studied. The population was the print, outdoor, or electronic media (radio and television). However, in Ethiopia, archives for electronic media were poorly managed in many stations and, where available, were not accessible to members of the public, even for research purposes. Therefore, the print medium was selected. Furthermore, the print media is a reputable source of information (Dearing et al., 1996). The researcher believes that electronic media for religious purposes have been used recently, but the purpose of this research is used to trace back to study the transition between secularity and post secularity periods.

The period under review for this study was from 1993 to 2021 from Hamer and 2014-2021 from Hintset. Hence, it was a useful timeline to see the trends for understanding how development issues have been reported. A multi-stage sampling technique was used for this study. The first stage of sampling, publication type, was purposive. "Hamer" and "Hintset" magazines have been identified as highly circulated and utilized by the Christian community. The second stage involves systematic random sampling and comprehensive sampling, which comprised fourteen (from Hamer) and seven (from Hintset) years editions of the selected period. Third, from the selected magazines, by using the available sampling technique all development issues (359 from Hamer and 326 from Hintset) were analyzed.

Data collection tool. The document was taken as a data collection tool. Quantitative contents were collected from the selected 
magazines. To collect documented data, the researcher adapted Xiaoge's (2009) indicators as a codebook for the content analysis of the development agendas. These indicators were used as analytic dimensions for the analysis of the programs. As an adaptation, these indicators were modified to address the questions of this study. In this context, development refers to economic, social, historical, cultural, political, moral, peacebuilding/ conflict resolution, and natural resource management.

Codebook. The codebook has five main parts. The first part deals with development story types: economic, social, political, cultural, historical, moral, peace (conflict resolution) and natural resource development. The second part includes sources of development stories, which are classified into six: Sacred books, media, adherents, government organizations, non-governmental organizations, and celebrities. The third part deals with story actors, religious leaders (Orthodox), Adherents, Religious leaders (Protestant), Political leaders and Prophets. The fourth part explains the dominant frames: Morality frame, Conflict frame, Economic frame, Educative frame, Conservative, Political power, Exclusivist, Corruption, Social work, Attribution of responsibility, and Human-interest frame. The last part includes years of publication (1993, 1995, 1997 ...2021 from Hamer and 2014, 2015, 2016, 2017, 2018, 2019, 2020, 2021 from Hintset).

Inter-coder reliability. Inter-coder Reliability $=2^{*} m /(\mathrm{N} 1+\mathrm{N} 2)$ where; $m$ is the number of coding decisions on which the two coders agreed; N1 and $\mathrm{N} 2$ are the total numbers of coding decisions by the first and second coder, respectively, (Holsti, 1969) should be divided by two. The inter-coder reliability result was 0.87 . Hence, the coding continued as the reliability coefficient indicated reliability.

Data analysis. The data which were collected from the document were analyzed using descriptive and inferential statistics. From the documented data, the indicators were used as a starting point of analysis. They helped gain insights into the basic structure in which the development-oriented programs exhibited and narrated in religious media practice. To identify these indicators, the coders carefully read the stories. The first step was to read the whole story to get a general idea of what the story was all about. Coders ensured that the indicators were mutually exclusive and exhaustive, as advised by (Jensen, 2013). Findings were discussed in line with the scholarly works and theories within which the study was situated.

\section{Findings}

The findings of this study were presented in eight categories based on the nature of the data. The data include the frequency distribution of development types and their parts in both Hamer and Hintset magazines by using descriptive statistics. It also comprises the cross-tabulation between development types, sources of the story, story actors, and dominant frames in line with years of publication, which has been analyzed in frequency, percentage, and Chi-square.

To what extent has the issue of development been central to EOTC-Hamer and EEC- Hintset in Ethiopia? In Hamer magazine, from a total of 988 stories, 359 (36.3\%) of them were labeled as development stories. Similarly, in Hintset magazine, from a total of 778 stories, 326 (41.9\%) of them were considered as development issues. To label them, inclusion and exclusion criteria were used. Hence, stories, which were found in the front and back pages, like advertisements, thanks-giving opinions, and repetitive issues were excluded. However, stories that showed material and non-material advancements, worldly and after worldly issues, secular and non-secular issues, etc. have been labeled as development issues. As a result, a total of 685 development stories, $359(52.4 \%)$ and 326 (47.6\%) from Hamer and Hintset were analyzed consecutively. These stories were categorized as period 1 and period 2. Period 1 in Hamer ranges from 1993 to 2005, which accounted for 167 (46.5\%) development stories, and Period 2 ranges from 2007 to 2021, which had 192 (53.5\%) development stories. Correspondingly, Period 1 in Hintset is categorized as 2014 to 2017 that covered 239 (73.3\%), and Period 2, which ranges from 2018 to 2021 had 87 (26.7\%) of the total development stories found in Hintset magazine.

What are the differences/similarities between the development content priorities, dominant sources, story actors, and dominant frames of Hamer and Hintset magazines during different periods of publications in Ethiopia? We present the data for cross-tabulation analysis. These are selected to show the validity of certain interactions of the data and to highlight certain salient points. We used and compared data from Hamer and Hintset magazines about development issues in the following multi categorical tables, as this perhaps shows the relationship between variables and better statistical validity.

Do economic development stories, or, sources, or, story actors, or dominant frames have a relationship with years of publication in Hamer and, (or) Hintset magazines?. It is important here to reinforce the relationship between economic development stories with types of publication, years of publication, sources, story actors, and their dominant frames in the above table. The result in Table 1 indicated that from a total of $31(8.6 \%)$ economic development stories in Hamer magazine, 19 (61.3\%) of them were found in the second period. On the contrary, the remaining 12 (38.7\%) of them were found in the first period. The Pearson chisquare test result showed that (chi-square $=0.832, p=0.362$, and $p>0.05)$. This indicated the economic development stories did not have any relationship between years of publication. On the contrary, Hintset magazine covered 20 (6.1\%) economic development stories. Among these, 19 (95\%) of economic development stories were found in the first period. The rest 1 (5\%) of economic development issues existed in the second period. The Pearson chi-square test result showed that (chi-square $=5.122, p=0.024$, and $p<0.05$ ). This indicated the economic development stories had a relationship between years of publication.

The data in Table 1 indicated that for economic development issues, there were a total of six primary source categories referenced, with the highest numbers being adherents and sacred. The result revealed that dominant sources of economic development stories in Hamer magazine were Sacred, Media, Celebrities, Adherents, and religious organizations. In the first period, 6 (50\%) of sources of economic development stories were adherents. Religious organizations, 5 (41.7\%), were the second most frequently used sources in the stated period. Media, $1(8.3 \%)$ was the least found economic source in the first period. However, in the second period, religious organizations, 7 (36.8\%), were the most dominant sources of economic development stories. Sacred books, 5 (27.8\%), and media, $5(27.8 \%)$ were the second and third dominant sources. Celebrities $2(10.5 \%)$ and adherents $2(10.5 \%)$ were the least frequently sources of the period. The Pearson chisquare test result showed that (chi-square $=17.245, p=0.093$, and $p>0.05$ ). This indicated the economic development stories sources did not have any relationship between years of publication.

Furthermore, in Hintset magazine, adherents 12 (62.2\%) were the most frequent sources of economic development stories. 


\begin{tabular}{|c|c|c|c|c|c|c|c|c|c|c|c|c|c|}
\hline \multicolumn{2}{|l|}{ Variables } & \multicolumn{4}{|c|}{ Hamer } & \multicolumn{4}{|c|}{ Hintset } & \multicolumn{2}{|c|}{ Chi-square } & \multicolumn{2}{|l|}{$p$-value } \\
\hline \multicolumn{2}{|c|}{ Years of publication (categorical) } & \multicolumn{2}{|c|}{ 1993-2005 } & \multicolumn{2}{|c|}{ 2007-2021 } & \multicolumn{2}{|c|}{ 2014-2017 } & \multicolumn{2}{|c|}{ 2018-2021 } & $\begin{array}{r}\text { Hamer } \\
0.832\end{array}$ & $\begin{array}{r}\text { Hintset } \\
5.122\end{array}$ & $\frac{\text { Hamer }}{0.362}$ & $\frac{\text { Hintset }}{0.024}$ \\
\hline \multirow[t]{5}{*}{ Sources of the story } & Sacred & - & - & 5 & 100 & - & - & - & & 17.245 & 19.150 & 0.093 & 0.004 \\
\hline & Media & 1 & 25 & 3 & 75 & 4 & 100 & - & - & & & & \\
\hline & Celebrities & - & - & 2 & 100 & 1 & 100 & - & & & & & \\
\hline & Adherents & 6 & 75 & 2 & 25 & 12 & 92.3 & 1 & 7.7 & & & & \\
\hline & ROs & 5 & 41.7 & 7 & 58.3 & 2 & 100 & - & - & & & & \\
\hline Story actors & Leaders EOTC & 8 & 50 & 8 & 50 & - & & - & & 43.407 & 6.984 & 0.000 & 0.000 \\
\hline \multirow{6}{*}{ Dominant Frames } & Conflict & - & & - & & - & & 1 & 100 & & & & \\
\hline & Economic & 10 & 50 & 10 & 50 & 10 & 100 & - & - & & & & \\
\hline & Educative & - & - & 1 & 100 & - & - & - & - & & & & \\
\hline & Social work & 2 & 66.7 & 1 & 33.3 & 4 & 100 & - & - & & & & \\
\hline & Responsibility & - & - & 2 & 100 & 4 & 100 & - & - & & & & \\
\hline & Human interest & - & - & 4 & 100 & 1 & 100 & - & - & & & & \\
\hline
\end{tabular}

Media 4 (21.1\%), and religious organizations $2(10.1 \%)$ were the second and third frequently used sources in the first period whereas celebrity, $1(5.3 \%)$ was the least economic development source during the first period. On the other hand, adherent, 1 $(100 \%)$ was the only source in the second period. The Pearson chi-square test result showed that (chi-square $=19, p=0.004$, and $p<0.05$ ). The Chi-square result has also solidified the identified trend, with a $p$-value lower than the conventional significance level. This indicated the economic development story sources had the relationship between years of publication.

To pursue the objective of analyzing the actors of the economic development stories, the researcher examined whether stories introduced different actors, which actors were included and quoted, and the weight that each actor had in the coverage. The finding in Table 1 revealed that EOTC leaders, 8 (66.7\%), and adherents, $4(33.3 \%)$ were economic development story actors in the first period. However, in the second period, besides EOTC leaders, $8(42.1 \%)$, and adherents, $3(15.8 \%)$, political leaders 4 $(21.1 \%)$, prophets $3(15.9 \%)$, and protestant leader, 1 (5.3\%) were economic development story actors. The Pearson chi-square test result showed that (chi-square $=43.407, p=0.000$, and $p<0.05$ ). This indicated the economic development story actors had the relationship between years of publication.

Moreover, in the Hintset magazine, adherents, 12 (63.2\%) and 7 (36.4\%) were the dominant economic development story actors in the first period. On the contrary, in the second period, only 1 (100\%) of economic development actor was adherents. The Pearson chi-square test result showed that (chi-square $=6.984$, $p=0.000$, and $p>0.05$ ). This indicated the economic development story actors did not have any relationship between years of publication. The result also revealed that seven dominant frames were found in both magazines and periods. Economic development frame, $10(83.3 \%)$ was an equally dominant frame in the stated periods in Hamer magazine.

Besides the economic development frame, social development frames $2(16.7 \%)$ in the first period. Similarly, human-interest frames $4(21.1 \%)$, responsibility frames, $2(10.5 \%)$, social work frames, $1(5.3 \%)$, and educative frames, $1(5.3 \%)$ in the second period. The Pearson chi-square test result showed that (chisquare $=127.313, p=0.000$, and $p<0.05$ ). This indicated the types of frames had a relationship between years of publication. Economic development frames, 10 (52.6\%) were also the most frequently found frames in Hintset magazine during the first period. Moreover, social work frames, $4(21.1 \%)$, and responsibility frames, 4 (21.1\%) were the second most frequently occurred frames in the first period. On the other hand, the human-interest frame, $1(5.3 \%)$ the least frequently found the frame in economic development stories. Whereas in the second period, only conflict frame, $1(100 \%)$ was found. The Pearson chi-square test result showed that (chi-square $=123.299, p=0.000$, and $p<0.05$ ). The Chi-square result has also solidified the identified trend, with a $p$ value lower than the conventional significance level. This indicated the kinds of frames had a relationship between years of publication.

Do social development stories, or, sources, or, story actors, or dominant frames have a relationship with years of publication in Hamer and, (or) Hintset magazines?. Social development stories were the most frequently found stories in both Hamer and Hintset magazines. From a total of 359 development stories in Hamer magazine, 117 (32.6\%) of them were social development issues whereas in Hintset magazine, from 326 development stories, 77 (23.6\%) were social development stories. The Pearson chi-square test result showed that (chi-square $=0.651, p=0.432$, and $p<0.05$ ). This indicated the social development issues did not have a relationship between years of publication.

As indicated in Table 2, 58 (49.6\%) of social development issues were found in the first period, and the remaining 59 $(50.4 \%)$ of them existed in the second period of Hamer magazine. Regarding social development story sources, Sacred was the most frequently taken source in both periods that was $25(45.5 \%)$ and $30(54.5 \%)$, consecutively. As it was compared to the same period, adherents $15(25.9 \%)$ and religious organizations, 11 (19\%) were the second and third most frequent sources of social development stories in the first period. Likewise, adherents, $17(28.8 \%)$ and religious organizations, 7 (11.9\%) were the second and third most 


\begin{tabular}{|c|c|c|c|c|c|c|c|c|c|c|c|c|c|}
\hline \multicolumn{2}{|l|}{ Variables } & \multicolumn{4}{|c|}{ Hamer } & \multicolumn{4}{|c|}{ Hintset } & \multicolumn{2}{|c|}{ Chi-square } & \multicolumn{2}{|l|}{$p$-value } \\
\hline \multicolumn{2}{|c|}{ Years of publication (categorical) } & \multicolumn{2}{|c|}{ 1993-2005 } & \multicolumn{2}{|c|}{ 2007-2021 } & \multicolumn{2}{|c|}{ 2014-2017 } & \multicolumn{2}{|c|}{ 2018-2021 } & Hamer & $\begin{array}{r}\text { Hintset } \\
6.207\end{array}$ & Hamer & Hintset \\
\hline \multirow[t]{6}{*}{ Sources of the story } & Sacred & 25 & 45.5 & 30 & 54.5 & 21 & 63.7 & 11 & 33.3 & 35.065 & 17.738 & 0.000 & 0.003 \\
\hline & Media & 7 & 77.8 & 2 & 22.2 & 6 & 40 & 9 & 60 & & & & \\
\hline & Celebrities & - & & - & & 2 & 66.7 & 1 & 33.3 & & & & \\
\hline & Adherents & 15 & 46.9 & 17 & 53.1 & 6 & 66.7 & 3 & 33.3 & & & & \\
\hline & ROs & 11 & 61.1 & 7 & 38.9 & 13 & 72.2 & 5 & 27.8 & & & & \\
\hline & NGOs & 1 & 25 & 3 & 75 & - & & - & & & & & \\
\hline \multirow[t]{10}{*}{ Dominant frames } & Morality & 2 & 14.3 & 12 & 85.7 & 5 & 41.7 & 7 & 58.3 & 205.600 & 138.081 & 0.000 & 0.000 \\
\hline & Conflict & - & - & 3 & 100 & - & - & - & - & & & & \\
\hline & Economic & 2 & 66.7 & 1 & 33.3 & - & - & - & - & & & & \\
\hline & Educative & 46 & 54.1 & 39 & 45.9 & 30 & 73.2 & 11 & 26.8 & & & & \\
\hline & Conservative & - & & - & & 1 & 50 & 1 & 50 & & & & \\
\hline & Exclusivist & 1 & 100 & - & - & 1 & 100 & - & - & & & & \\
\hline & Corruption & - & & - & - & 3 & 100 & - & - & & & & \\
\hline & Social work & 2 & 40 & 3 & 60 & 5 & 55.6 & 4 & 44.4 & & & & \\
\hline & Responsibility & 2 & 66.7 & 1 & 33.3 & 2 & 40 & 3 & 60 & & & & \\
\hline & Human interest & 3 & 100 & - & - & 1 & 25 & 3 & 75 & & & & \\
\hline
\end{tabular}

occurred social development stories in the second period. NGOs, 1 (1.7\%), and media, $7(12.1 \%)$ were the least and second least frequently used social development story sources in the first period. Conversely, media, $2(3.4 \%)$ and NGOs, 3 (5.1\%) were the least and second least found social development sources in the second period of Hamer magazine. The Pearson chi-square test result showed that (chi-square $=35.065, p=0.000$, and $p<0.05$ ). This indicated the kinds of social development sources of the story had the relationship between years of publication. Concerning sources, Sacred books were also the most frequent sources of social development stories in the first, 21 (48.8\%), and second $11(37.9 \%)$ period of social development stories in Hintset magazine. Religious organizations, $13(27.1 \%)$ in the first period and media, $9(31 \%)$ in period 2 were the second most frequently found social development sources. In the first period, however, media and adherents were equally $6(12.5 \%)$ the third dominant social development sources. Religious organizations, 5 (17.2\%) was the third dominant social development story source in the second period. Adherents, $3(10.3 \%)$ was the second least frequently used source in period 2. Celebrities, which were found in the first period $2(4.2 \%)$ and 1 (3.4\%) in the second period, were the scarcest sourced social development stories. The Pearson chi-square test result exhibited that (chi-square $=17.738$, $p=0.003$, and $p<0.05)$. This indicated the kinds of social development sources of the story had the relationship between years of publication.

As identified in Table 2, there were six dominant social development story actors in both Hamer and Hintset magazines. Adherents, $36(62.1 \%)$ in the first period and 31 (52.5\%) in period 2 , were the most dominant social development story actors in Hamer magazine. Prophets were also the second most frequently found story actors in both the first 19 (32.8\%) and second 16 (27.1\%) periods. Similarly, EOTC leaders were the third frequent social development actors in periods 1, $2(3.4 \%)$ and periods 2, 9 (15.3\%). Celebrities, 3 (5.1\%) in period 2 and Protestant leaders, 1
$(1.7 \%)$ in period 1 were the least mentioned social development actors in Hamer magazine. The Pearson chi-square test result showed that (chi-square $=35.065, p=0.000$, and $p<0.05$ ). This indicated the kinds of social development story actors had the relationship between years of publication.

Such patterns of distribution were similar for Hintset magazine, adherents, $21(43.8 \%)$ in period 1 and $14(48.3 \%)$ in period 2 were the most frequently found social development actors. Moreover, prophets, $13(27.1 \%)$ and $8(27.6 \%)$ were the second most frequently stated social development actors in both periods consecutively. Protestant leaders, $12(25 \%)$ in the first period and $5(17.2 \%)$ in the second period were the third dominant actors in the magazine, However, EOTC leaders, 2 (4.2\%) in period 1 and celebrities, $2(6.9 \%)$ in period 2 were the scarcest social development actors in Hintset magazine. The Pearson chisquare test result showed that (chi-square $=17.738, p=0.003$, and $p<0.05)$. This indicated the kinds of social development story actors had the relationship between years of publication. The finding in Table 2 indicated that there were about ten kinds of development frames in Hamer and Hintset magazines during the studied periods. The educative frame was the most dominant in both studied magazine periods.

In Hamer magazine, 46 (79.3\%) and $39(66.1 \%)$ of frames were educative frames in the first and second periods consecutively. Morality frame, $12(20.3 \%)$ was the second most dominant frame in Hamer magazine during the second period whereas the human-interest frame, 3 (5.1\%) was the second dominant frame in the first period. Responsibility, social work, economic, and morality frames, 2 (3.4\%) were the third most and second least frequently found social development frames in Hamer magazine during the first period. Similarly, conflict and social work frame 3 (5.1\%) were the second most dominant frames during the second period. Exclusivist frame, 1 (1.7\%) was the scarcest social development frame during the first period in Hamer magazine, while responsibility and economic development frames, $1(1.7 \%)$ 


\begin{tabular}{|c|c|c|c|c|c|c|c|c|c|c|c|c|c|}
\hline \multicolumn{2}{|l|}{ Variables } & \multicolumn{4}{|c|}{ Hamer } & \multicolumn{4}{|c|}{ Hintset } & \multicolumn{2}{|c|}{ Chi-square } & \multicolumn{2}{|l|}{$p$-value } \\
\hline \multicolumn{2}{|c|}{ Years of publication (categorical) } & \multicolumn{2}{|c|}{ 1993-2005 } & \multicolumn{2}{|c|}{ 2007-2021 } & \multicolumn{2}{|c|}{ 2014-2017 } & \multicolumn{2}{|c|}{ 2018-2021 } & $\begin{array}{r}\text { Hamer } \\
0.370\end{array}$ & $\begin{array}{r}\text { Hintset } \\
2.912\end{array}$ & $\frac{\text { Hamer }}{0.667}$ & $\frac{\text { Hintset }}{0.110}$ \\
\hline \multirow[t]{6}{*}{ Sources of the story } & Sacred & - & - & 1 & 100 & 1 & 100 & - & - & 7.925 & 31.726 & 0.339 & 0.000 \\
\hline & Media & - & & - & - & 5 & 45.5 & 6 & 54.5 & & & & \\
\hline & Celebrities & - & - & - & - & 1 & 50 & 1 & 50 & & & & \\
\hline & Adherents & 3 & 75 & 1 & 25 & 2 & 50 & 2 & 50 & & & & \\
\hline & ROs & - & - & - & - & 4 & 100 & - & - & & & & \\
\hline & GOs & - & - & - & - & 3 & 60 & 2 & 40 & & & & \\
\hline \multirow[t]{8}{*}{ Dominant frames } & Conflict & - & & 1 & 100 & - & & - & & 14.957 & 176.118 & 0.092 & 0.000 \\
\hline & Educative & - & & 1 & 100 & - & & - & & & & & \\
\hline & Conservative & 1 & 100 & - & & - & & - & & & & & \\
\hline & Political power & - & & - & & 7 & 43.8 & 9 & 56.2 & & & & \\
\hline & Exclusivist & - & & - & & 3 & 100 & - & & & & & \\
\hline & Corruption & - & & - & & 1 & 100 & - & & & & & \\
\hline & Responsibility & 2 & 100 & - & & 4 & 66.7 & 2 & 33.3 & & & & \\
\hline & Human interest & - & - & - & - & 1 & 100 & - & - & & & & \\
\hline
\end{tabular}

were the scarcest in the second period. The Pearson chi-square test result showed that (chi-square $=205.600, p=0.000$, and $p<0.05$ ). This indicated in the social development stories, and the kinds of frames had a relationship between years of publication.

The finding also revealed that the educative frame in Hintset magazine was the most dominant one. It counted as $30(62.5 \%)$ and $11(37.9 \%)$ in the first and second periods consecutively. Morality and social work frames, 5 (10.4\%) in the first period equally, and morality, 7 (24.1\%) in the second period were the second most dominant frames in Hintset magazine. The corruption frame, $3(6.3 \%)$ in the first period, and social work frame, $4(13.8 \%)$ in the second period were the third most frequently found frames in Hintset magazine. Responsibility frame, $2(4.2 \%)$ was the second least frequently frames in period 1. Conservative, exclusivist, and human-interest frames, 1 (2.1\%) were equally the scarcest frames during the first period. Similarly, the conservative frame, $1(2.1 \%)$ was the last one in the second period of Hintset magazine. The Pearson chi-square test result exhibited that $($ chi-square $=138.081, p=0.000$, and $p<0.05$ ). The Chi-square result has also solidified the identified trend, with a $p$-value lower than the conventional significance level. This directed in the social development stories, and the kinds of frames had the relationship between years of publication.

Do political development stories, or, sources, or, story actors, or dominant frames have a relationship with years of publication in Hamer and, (or) Hintset magazines?. The finding in Table 3 disclosed that political development stories were the secondscarcest development stories, next to natural resource management themes. As it was compared between the two studied magazines, Hamer magazine covered only $5(1.4 \%)$ political development issues in both periods. However, Hintset magazine covered $27(8.3 \%)$ political development stories. Three $(60 \%)$ and $2(40 \%)$ of political development issues were found in the first and second periods in Hamer magazine. The Pearson chi-square test result exhibited that (chi-square $=0.370, p=0.667$, and $p>0.05)$. This showed that the political development stories did not relationship between years of publication. The result also showed that adherents, $3(100 \%)$ were the only source of political development stories in the first period in Hamer magazine. However, in the second period, sacred, 1 (50\%), and adherents, 1 (50\%) were equally sources of political development issues. The Pearson chi-square test result exhibited that (chi-square $=31.726$, $p=0.339$, and $p>0.05$ ). This showed that the political development stories sources did not relationship between years of publication in Hamer magazine.

Regarding the political development sources of Hintset magazine, it used five different sources; namely, sacred, media, celebrities, adherents, religious organizations, and government organizations. Among these, media, $5(31.3 \%)$ and $6(54.5 \%)$ were the most frequent source during the first and second periods consecutively. Religious organizations, 4 (25\%), and government organizations $3(18.8 \%)$ were the second and third political development sources in the first period. On the other hand, adherents, $2(18.2 \%)$ and government organizations, $2(18.2 \%)$ were equally the second most frequent sources during the second period. Adherents, $2(12.5 \%)$ were the second least frequently found sources of political development stories in Hintset magazine during the first period. Sacred, $1(6.3 \%)$ in the first period and celebrities in both first, 1 (6.3\%) and second, $1(9.1 \%)$ period, were the least frequent sources of political development stories. The Pearson chi-square test result exhibited that (chisquare $=31.726, p=0.000$, and $p<0.05$ ). The Chi-square result has also solidified the identified trend, with a $p$-value lower than the conventional significance level. This showed that Hintset political development story sources had a relationship between years of publication.

The finding also showed that 3 (100\%) of political development actors were adherents in Hamer magazine during the first period. In the second period, adherents, 1 (50\%), and prophets, $1(50 \%)$ were political development actors. The Pearson chi-square test result exhibited that (chi-square $=2.381, p=0.794$, and $p>0.05$ ). This showed that Hamer magazine's political development story sources did not have a relationship between years of publication. 
In Hintset magazine, there were about five kinds of dominant frames. Adherents, 7 (43.8\%) were the most dominant political development actors in the first period. Protestant leaders, 4 (25\%) and political leaders, $3(18.8 \%)$ were the second and third frequently found political development actors during the first period in Hintset magazine. Prophets and celebrities were equally $1(6.3 \%)$ the scarcest political development actors during the first period. During the second period, political development actors, 5 (45.5\%) and adherents, $3(27.3 \%)$ were the first and second most frequently found political development actors in Hintset magazine. On the contrary, protestant leaders, 1 (9.1\%) and celebrities, $2(18.2 \%)$ were the first and second-scarcest political development actors in the magazine. The Pearson chi-square test result exhibited that (chi-square $=56.234, p=0.000$, and $p<0.05$ ). This showed that the political development story actors in Hintset magazine had a relationship between years of publication.

As identified in the above table, there were three dominant frames in Hamer magazine. From these, responsibility, 2 (66.7\%) and conservative, $1(33.3 \%)$ frame were the first and second most dominant frames in Hamer magazine during the first period. On the contrary, conflict, 1 (50\%) and educative, 1 (50\%) frame were found during the second period. The Pearson chi-square test result exhibited that (chi-square $=14.957, p=0.092$, and $p>05$ ). This showed that Hamer magazine's political development story frames did not have a relationship between years of publication.

Moreover, in Hintset magazine, there were five dominant frames in both periods. During the first period, political power, 7 (43.8\%), and responsibility, 4 (25\%) frames were the most and second most frequent dominant frames. Exclusivist frame, 3 (18.8\%) was the second least frequently found frame next to corruption, $1(6.3 \%)$ and human interest, 1 (6.3\%) frame. In period 2, political power, 9 $(81.8 \%)$ and responsibility, 2 (18.2\%) frames were found. The Pearson chi-square test result exhibited that (chi-square $=14.957$, $p=0.092$, and $p>0.05$ ). This showed that the Hintset magazine political development story dominant frames did not have a relationship between years of publication (Table 4).

Do cultural development stories, or, sources, or, story actors, or dominant frames have a relationship with years of publication in Hamer and, (or) Hintset magazines?. Cultural development stories were one of the least frequently covered issues in both Hamer and Hintset magazines. As the result in Table 7 indicated that $24(6.7 \%)$ stories in Hamer and $5(1.5 \%)$ in Hintset were found. From a total of 24 stories in Hamer magazine, 8 (33.3\%) of them were exhibited in period 1 and the remaining $16(66.7 \%)$ existed during the second period. The Pearson chi-square test result exhibited that (chisquare $=1.797, p=0.208$, and $p>0.05$ ). This showed that the Hamer magazine cultural development stories did not have a relationship between years of publication. However, in Hintset magazine, all stories, 5 (100\%) of cultural development stories were found only during the first period. The Pearson chi-square test result exhibited that (chi-square $=1.848, p=0.330$, and $p>05$ ). This showed that the Hintset magazine cultural development stories did not have a relationship between years of publication.

Regarding cultural development story sources, adherents, 5 (62.5\%), media, 2 (25\%), and religious organizations, 1 (12.5\%) were sources of stories in the first period of Hamer magazine. On the other hand, religious organizations, 9 (56.3\%), sacred, 4 (25\%), media, 2 (12.5\%), and celebrities, 1 (6.3\%) were the dominant sources in the second period. The Pearson chi-square test result demonstrated that (chi-square $=7.549, p=0.374$, and $p>0.05)$. This showed that the Hamer magazine cultural development story sources did not have a relationship between years of publication. Hintset magazine also had three sources of cultural development sources. Sacred, 2 (40\%) and media, 2 (40\%) were the dominant sources; nevertheless, celebrity, 1 (20\%) was the least stated sources of cultural development stories. The Pearson chi-square test result demonstrated that (chisquare $=5.382, p=0.496$, and $p>0.05$ ). This showed that the Hintset magazine cultural development story sources did not have a relationship between years of publication. The result in the above table presented that adherents, 8 (100\%) were the only cultural development actor in Hamer magazine during the first period. On the contrary, there were four cultural development story actors in the second period. Adherents, $8(50 \%)$, EOTC leaders, $4(25 \%)$, protestant leaders, $3(18.8 \%)$, and $1(6.3 \%)$ were sources that were found during the second period of Hamer magazine. The Pearson chi-square test result demonstrated that (chi-square $=8.347, p=0.138$, and $p>0.05$ ). This showed that the Hamer magazine cultural development story actors did not have a relationship between years of publication. There was only one cultural development story actor in Hintset magazine. It was adherents, 5 (100\%). The Pearson chi-square test result demonstrated that (chi-square $=4.955, p=0.421$, and $p>0.05$ ). This showed that the Hintset magazine cultural development story actors did not have a relationship between years of publication.

Cultural development stories were framed differently across magazines and the periods of years of publication. In Hamer magazine, responsibility, $5(62.5 \%)$ and conservative, $3(37.5 \%)$ frames were the two dominant frames that were found during the first period. However, in the second period, there were about eight types of frames were exhibited. From these, responsibility, 3 $(18.8 \%)$ and human interest, $3(18.8 \%)$ were the most frequently used frames. Exclusivist, 2 (12.5\%), conservative, 2 (12.5\%), educative, $2(12.5 \%)$ and morality, $2(12.5 \%)$ were the second most frequently found frames. On the other hand, economic, 1 $(6.3 \%)$ and corruption, 1 (6.3\%) frame were the scarcest frames during the second period. The Pearson chi-square test result demonstrated that (chi-square $=66.933, p=0.000$, and $p<0.05$ ). This showed that the Hamer magazine cultural development story dominant frames had a relationship between years of publication. In Hintset magazine, also three types of frames were found. They were educative, 2 (40\%), conservative, 2 (40\%), and human interest, $1(20 \%)$ frame. The Pearson chi-square test result demonstrated that (chi-square $=26.095, p=0.004$, and $p<0.05$ ). The Chi-square result has also solidified the identified trend, with a $p$-value lower than the conventional significance level. This showed that the Hintset magazine cultural development story dominant frames had a relationship between years of publication.

Do historical development stories, or, sources, or, story actors, or dominant frames have a relationship with years of publication in Hamer and, (or) Hintset magazines?. Historical development stories were the fourth frequently covered development stories in both Hamer and Hintset magazines. As they were compared to one another, Hintset had more historical development stories than Hamer magazine. Hamer magazine covered 47 (13.1\%) stories. From these, 28 (59.6\%) and 19 (40.4\%) were found during the first and second periods consecutively. The Pearson chisquare test result demonstrated that (chi-square $=3.706$, $p=0.061$, and $p>0.05)$. This showed that Hamer magazine's historical development stories did not have a relationship between years of publication. Similarly, Hintset magazine covered 57 (17.5\%) historical development stories, 46 (80.7\%) in the first period, and $11(19.3 \%)$ in the second period. The Pearson chisquare test result demonstrated that (chi-square $=1.928$, $p=0.189$, and $p>0.05)$. This showed that Hintset magazine's historical development stories did not have a relationship between years of publication.

As it can be seen from Table 5, religious organizations, 10 (35.7\%) were the most frequent historical development sources in Hamer magazine during the first period. Adherents, 7 (25\%) and 


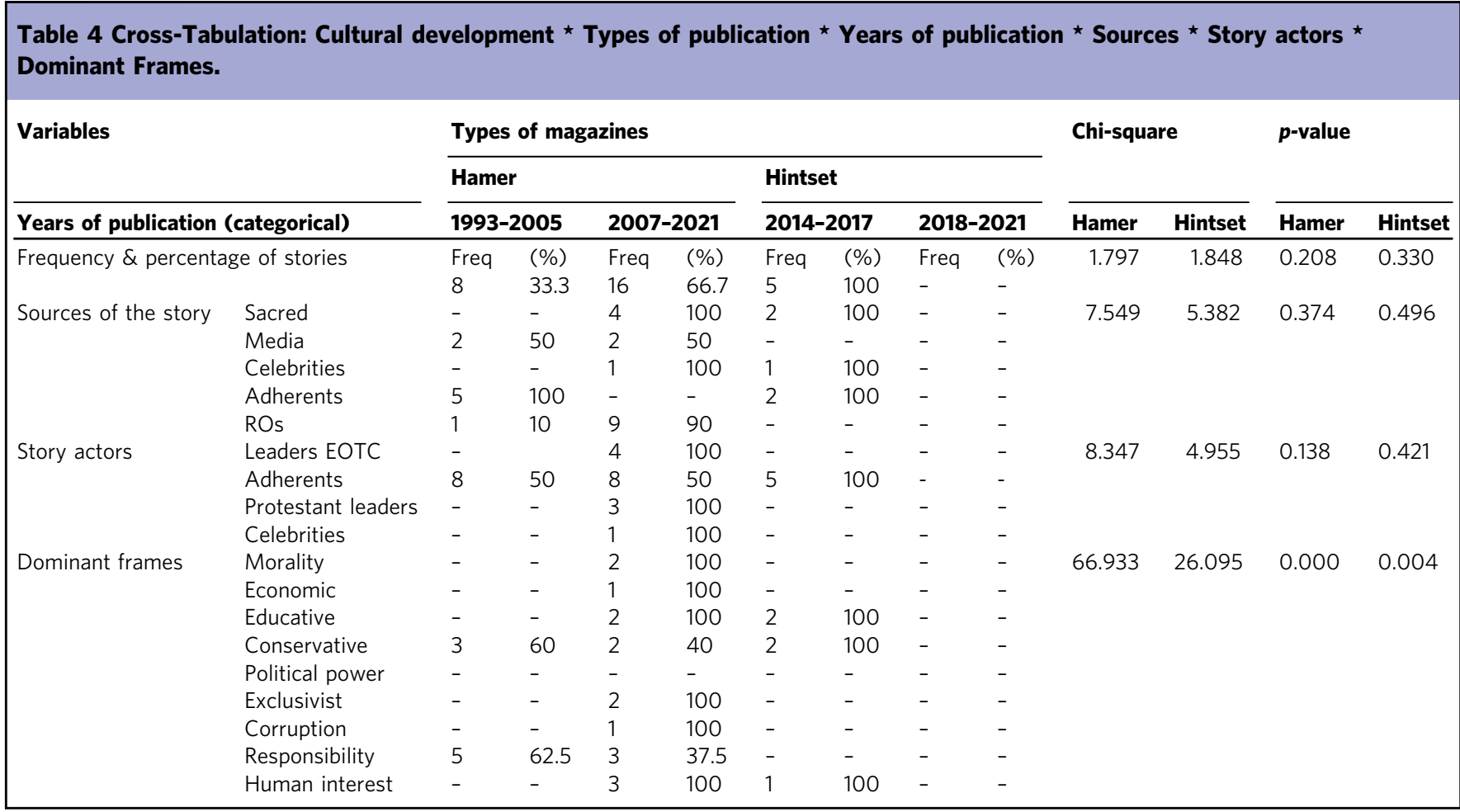

sacred books, 7 (25\%) were the second most frequent sources in that period. Media, 4 (14.3\%), however, was the least frequent historical development source in the first period. During the second period, religious organizations, $8(42.1 \%)$, and media, 8 $(42.1 \%)$ were the most frequent historical development sources. Sacred books, $2(10.2 \%)$ and adherents, 1 (5.3\%) were the second and third frequent historical development story sources in the Hamer magazine. The Pearson chi-square test result demonstrated that (chi-square $=19.608, p=0.006$, and $p<0.05$ ). This showed that the Hamer magazine historical development story sources had a relationship between years of publication.

In Hintset magazine, a great number of sources were found during the first period. Adherents, 15 (32.6\%), media, 12 (26.1\%), and religious organizations, 11 (23.9\%) were ranked first up to third frequent historical development story sources in period 1. On the contrary, celebrities, $2(4.3 \%)$, government organizations, $3(6.5 \%)$, and sacred books, $3(6.5 \%)$ were the first and second least frequent sources of historical development stories during the first period. Media, 5 (45.5\%) and adherents, 4 (36.4\%) were the most and second most frequent historical development sources during the second period while sacred, 1 (9.1\%) and religious organizations, 1 (9.1\%) were the scarcest historical development stories in the period. The Pearson chi-square test result demonstrated that (chi-square $=12.056, p=0.061$, and $p>0.05)$. This showed that the Hintset magazine historical development story sources did not have a relationship between years of publication.

Concerning historical development actors, EOTC leaders, 14 $(50 \%)$ in the first period and $9(32.1 \%)$ in the second period, were the most dominant ones in both periods in Hamer magazine. Prophets, 7 (25\%) were the second most frequent sources in the first period while adherents, 6 (31.6\%) were in the second period. Adherents, $6(21.4 \%)$ were the third most frequent in period 1. Nevertheless, protestant leaders, $2(7.1 \%)$ were the least frequent in period 1 and political leaders, $3(15.8 \%)$ were the second least in the second period next to prophets, $1(5.3 \%)$. The Pearson chisquare test result demonstrated that (chi-square $=45.361$, $p=0.000$, and $p<0.05$ ). This showed that the Hamer magazine historical development story actors had a relationship between years of publication.

The most frequent historical development actors in Hintset magazine were adherents, in both first, 23 (50\%) and second, 5 $(45.5 \%)$ periods. However, protestant leaders, 16 (34.8\%) were the second most frequent in the first period. EOTC leaders were the second most frequent during the second period, $3(27.3 \%)$, and the third one in the first period, 3 (6.5\%). Political leaders, 2 (4.3\%), and prophets, $2(4.3 \%)$ were the scarcest historical development story actors during the first period whereas, in the second-period prophets, 1 (9.1\%) and protestant leaders, 2 $(18.2 \%)$ were the least and second least frequent historical development stories. The Pearson chi-square test result confirmed that (chi-square $=17.601, p=0.003$, and $p<0.05$ ). This showed that the Hintset magazine historical development story actors had a relationship between years of publication.

Historical development stories were framed differently. In Hamer magazine, the human-interest frame, 12 (42.9\%) was the most dominant one during the first period. In the responsibility frame, $6(21.4 \%)$ were second frequent in the first period, and 12 $(63.2 \%)$ were most frequent during the second period. Educative frame, $3(10.7 \%)$ was the third most frequent frame during the first period. Social work, 2 (7.1\%), exclusivist, 2 (7.1\%), and morality, $2(7.1 \%)$ were the second least frequent frames from historical development stories during the first period. Conflict frame, 1 (3.6\%) was the least frequently found stories during the first period of Hamer magazine. Next to the responsibility frame, human interest, exclusivist, and morality frames were the second dominant frame during the second period. Conservative frame, 1 (5.3\%) was the scarcest frame in Hamer magazine during period 2. The Pearson chi-square test result demonstrated that (chisquare $=71.523, p=0.000$, and $p<0.05$ ). This showed that the Hamer magazine historical development story dominant frames had a relationship between years of publication.

Regarding Hintset magazine, the human-interest frame was the most frequent frame during the first, 16 (34.8\%), and the second, $4(36.4 \%)$ periods. Exclusivist, 6 (13\%) frame was the second most frequent frame during the first period. Responsibility, 5 (10.9\%) 


\begin{tabular}{|c|c|c|c|c|c|c|c|c|c|c|c|c|c|}
\hline \multicolumn{2}{|l|}{ Variables } & \multicolumn{4}{|c|}{ Hamer } & \multicolumn{4}{|c|}{ Hintset } & \multicolumn{2}{|c|}{ Chi-square } & \multicolumn{2}{|l|}{$p$-value } \\
\hline \multicolumn{2}{|c|}{ Years of publication (categorical) } & \multicolumn{2}{|c|}{ 1993-2005 } & \multicolumn{2}{|c|}{ 2007-2021 } & \multicolumn{2}{|c|}{ 2014-2017 } & \multicolumn{2}{|c|}{ 2018-2021 } & $\begin{array}{r}\text { Hamer } \\
3.706\end{array}$ & $\begin{array}{r}\text { Hintset } \\
1.928\end{array}$ & $\frac{\text { Hamer }}{0.061}$ & $\begin{array}{l}\text { Hintset } \\
0.189\end{array}$ \\
\hline \multirow[t]{6}{*}{ Sources of the story } & Sacred & 7 & 77.8 & 2 & 22.2 & 3 & 75 & 1 & 25 & 19.608 & 12.056 & 0.006 & 0.061 \\
\hline & Media & 4 & 33.3 & 8 & 66.7 & 12 & 70.6 & 5 & 29.4 & & & & \\
\hline & Celebrities & - & - & - & - & 2 & 100 & - & - & & & & \\
\hline & Adherents & 7 & 87.5 & 1 & 12.5 & 15 & 78.9 & 4 & 21.1 & & & & \\
\hline & $\mathrm{ROs}$ & 10 & 55.5 & 8 & 44.5 & 11 & 91.7 & 1 & 8.3 & & & & \\
\hline & GOs & - & - & - & - & 3 & 100 & - & - & & & & \\
\hline \multirow[t]{11}{*}{ Dominant frames } & Morality & 2 & 50 & 2 & 50 & 2 & 66.7 & 1 & 33.3 & 71.523 & 45.374 & 0.000 & 0.000 \\
\hline & Conflict & 1 & 100 & - & - & 5 & 83.3 & 1 & 16.7 & & & & \\
\hline & Economic & - & - & - & - & 1 & 100 & - & - & & & & \\
\hline & Educative & 3 & 100 & - & - & 3 & 100 & - & - & & & & \\
\hline & Conservative & - & - & 1 & 100 & 3 & 75 & 1 & 25 & & & & \\
\hline & Political power & - & - & - & - & 1 & 100 & - & - & & & & \\
\hline & Exclusivist & 2 & 50 & 2 & 50 & 6 & 100 & - & & & & & \\
\hline & Corruption & - & & - & & 2 & 66.7 & 1 & 33.3 & & & & \\
\hline & Social work & 2 & 100 & - & - & 2 & 100 & - & - & & & & \\
\hline & Responsibility & 6 & 33.3 & 12 & 666.7 & 5 & 62.5 & 3 & 37.5 & & & & \\
\hline & Human interest & 12 & 85.7 & 2 & 14.3 & 16 & 80 & 4 & 20 & & & & \\
\hline
\end{tabular}

and conflict, $5(10.9 \%)$ frames were the third most frequent frame during period 1 . On the contrary, responsibility, $3(27.3 \%)$ was the second most frequent frame during the second period. Morality, 1 (9.1\%), conflict, 1 (9.1\%), conservative, $1(9.1 \%)$ and corruption frames were the scarcest frames during the second period. Educative, 3 (27.3\%) and conservative, 3 (27.3\%) frames were the third least frequent frames during the second period. Corruption, 2 (4.3\%), social work, 2 (4.3\%), and morality, 2 $(4.3 \%)$ frames were the second least frequent frames in period 1. Economic, $1(2.2 \%)$ and political power, 1 (2.2\%) frame were the scarcest frames during the first period. The Pearson chi-square test result demonstrated that (chi-square $=45.374, p=0.000$, and $p<0.05)$. This showed that the Hintset magazine historical development story dominant frames had the relationship between years of publication.

Do economic development stories, or, sources, or, story actors, or dominant frames have a relationship with years of publication in Hamer and, (or) Hintset magazines?. Moral development stories were the second most frequently found issues in both Hamer and Hintset magazines. Specifically, Hamer covered 71 (19.8\%) moral development stories. Of these, $44(62 \%)$ were found in the second period, while $27(38 \%)$ of the remaining were found during the first period. The Pearson chi-square test result demonstrated that (chi-square $=2.564, p=0.113$, and $p>0.05$ ). This showed that the Hamer magazine moral development stories did not have a relationship between years of publication. Hintset magazine also covered $73(22.4 \%)$ moral development stories in both periods. Among these, 50(68.5\%) were found in the first period, and 23 $(31.5 \%)$ of them were covered during the second period. The Pearson chi-square test result demonstrated that (chisquare $=1.117, p=0.296$, and $p>0.05$ ). This showed that the Hintset magazine moral development stories did not have a relationship between years of publication.
Most of the moral development sources were sacred books in Hamer magazine in both periods. During the first period, sacred $11(40.7 \%)$, religious organizations, 10 (37\%), and adherents, 6 $(22.2 \%)$ were sources of moral development stories. Similarly, in the second period, sacred, $21(47.7 \%)$, religious organizations, 13 $(29.5 \%)$ and adherents, $8(18.2 \%)$ were the most frequent moral development sources; however, media, 2 (4.5\%) were the scarcest sources during the second period. The Pearson chi-square test result demonstrated that (chi-square $=14.835, p=0.038$, and $p>0.05$ ). This showed that the Hamer magazine moral development story sources did not have a relationship between years of publication.

Furthermore, as indicated in Table 6, Hintset magazine covered more moral development story sources from sacred books. Specifically, sacred books were the most frequent in both first, 16 (32\%) and second, $9(39.1 \%)$ periods. Adherents, $14(28 \%)$ and media, $12(24 \%)$ were the second and third most frequent sources in Hintset magazine during the first period. Nevertheless, celebrities, $3(6 \%)$ and religious organizations, $3(6 \%)$ were the second least frequent sources next to government, $1(2 \%)$ and non-government organizations, 1 (2\%). During the second period, media, $8(34.8 \%)$ were the second most frequent moral development sources. On the other hand, adherents, $4(17.4 \%)$ and celebrities, 2 (8.7\%) were the second and first least frequent moral development sources in Hintset magazine during the second period. The Pearson chi-square test result demonstrated that (chi-square $=16.881, p=0.010$, and $p<0.05$ ). This showed that the Hintset magazine moral development story sources did not have a relationship between years of publication.

As it can be seen from the above table, adherents in Hamer magazine were the most dominant moral development actors in both the first, $24(88.9 \%)$ and the second, $27(61.4 \% \%)$ periods. Prophets, $2(7.4 \%)$, and celebrities, $1(3.7 \%)$ were the second and third frequent moral development story actors during the first 


\begin{tabular}{|c|c|c|c|c|c|c|c|c|c|c|c|c|c|}
\hline \multirow{2}{*}{\multicolumn{2}{|c|}{ Variables }} & \multicolumn{8}{|c|}{ Types of magazines } & \multirow{2}{*}{\multicolumn{2}{|c|}{ Chi-square }} & \multirow{2}{*}{\multicolumn{2}{|c|}{$p$-value }} \\
\hline & & \multicolumn{4}{|c|}{ Hamer } & \multicolumn{4}{|c|}{ Hintset } & & & & \\
\hline \multicolumn{2}{|c|}{ Years of publication (categorical) } & \multicolumn{2}{|c|}{ 1993-2005 } & \multicolumn{2}{|c|}{ 2007-2021 } & \multicolumn{2}{|c|}{ 2014-2017 } & \multicolumn{2}{|c|}{ 2018-2021 } & $\begin{array}{r}\text { Hamer } \\
2.564\end{array}$ & $\begin{array}{c}\text { Hintset } \\
1.117\end{array}$ & $\begin{array}{l}\text { Hamer } \\
0.113\end{array}$ & $\begin{array}{l}\text { Hintset } \\
0.296\end{array}$ \\
\hline \multirow{7}{*}{ Sources of the story } & Sacred & 11 & 34.4 & 21 & 65.6 & 16 & 64 & 9 & 36 & 14.835 & 16.881 & 0.038 & 0.010 \\
\hline & Media & - & - & 2 & 100 & 12 & 60 & 8 & 40 & & & & \\
\hline & Celebrities & - & - & - & - & 3 & 60 & 2 & 40 & & & & \\
\hline & Adherents & 6 & 42.9 & 8 & 57.1 & 14 & 77.8 & 4 & 22.2 & & & & \\
\hline & ROs & 10 & 43.5 & 13 & 56.5 & 3 & 100 & - & - & & & & \\
\hline & GOs & - & - & - & - & 1 & 100 & - & - & & & & \\
\hline & NGOs & - & - & - & - & 1 & 100 & - & - & & & & \\
\hline Story actors & Celebrities & 1 & 50 & 1 & 50 & 3 & 100 & - & - & & & & \\
\hline \multirow[t]{10}{*}{ Dominant frames } & Morality & 19 & 41.3 & 27 & 58.7 & 8 & 44.4 & 10 & 55.6 & 109.116 & 66.130 & 0.000 & 0.000 \\
\hline & Conflict & 1 & 25 & 3 & 75 & - & - & 2 & 100 & & & & \\
\hline & Economic & - & - & 9 & 100 & - & - & 3 & 100 & & & & \\
\hline & Educative & - & - & - & - & 2 & 100 & - & - & & & & \\
\hline & Conservative & - & - & - & - & 1 & 100 & - & - & & & & \\
\hline & Exclusivist & - & - & - & - & 1 & 100 & - & - & & & & \\
\hline & Corruption & - & - & 1 & 100 & 7 & 53.8 & 6 & 46.2 & & & & \\
\hline & Social work & - & - & 1 & 100 & 6 & 100 & - & - & & & & \\
\hline & Responsibility & 6 & 66.7 & 3 & 33.3 & 5 & 71.4 & 2 & 28.6 & & & & \\
\hline & Human interest & 1 & 100 & - & - & 9 & 100 & - & - & & & & \\
\hline
\end{tabular}

period. Similarly, prophets, $14(31.8 \%)$ were the second most frequent moral development actors in period 2 . On the contrary, celebrities, $1(2.3 \%)$ and EOTC leaders, 2 (4.5\%) were the least and second least frequent development actors during the second period. The Pearson chi-square test result demonstrated that (chisquare $=27.406, p=0.000$, and $p<0.05)$. The Chi-square result has also solidified the identified trend, with a $p$-value lower than the conventional significance level. This showed that the Hamer magazine moral development story actors had a relationship between years of publication. Likewise, in Hintset magazine, adherents were the most frequent moral development stories during the first, 30 (60\%), and second, 17 (73.9\%) periods. Protestant leaders, $11(22 \%)$ and prophets, $5(10 \%)$ were the second and third frequently found moral development actors during the first period. However, EOTC leaders, 1 (2\%) and celebrities, $3(6 \%)$ were the scarcest and second-scarcest moral development actors in periods 1 . Protestant leaders, $2(8.7 \%)$ and prophets, $4(17.4 \%)$ were the least and second least frequently found moral development story actors during the second period. The Pearson chi-square test result demonstrated that (chisquare $=11.390, p=0.000$, and $p<0.044)$. This showed that the Hintset magazine moral development story actors had a relationship between years of publication.

The result in Table 6 indicated that the morality frame was the most dominant in both Hamer and Hintset magazines within the two periods. Morality, 19 (70.4\%) and responsibility, 6 (22.2\%) were the first and second most frequent dominant frames in Hamer magazine during period 1 . On the other hand, conflict, 1 (3.7\%), and human interest, $1(3.7 \%)$ were the least frequent frame during the first period. In the second period also morality, 27 (61.4\%) was the most dominant frame. Economic, 9 (20.5\%), conflict, $3(6.8 \%)$, and responsibility, $3(6.8 \%)$ were the second and third frequent frames in period 2. Corruption, 1 (2.3\%), and social work, $1(2.3 \%)$ were the scarcest frame during the second period. The Pearson chi-square test result demonstrated that (chisquare $=109.116, p=0.000$, and $p<0.05$ ). The Chi-square result has also solidified the identified trend, with a $p$-value lower than the conventional significance level. This showed that the Hamer magazine moral development frame had a relationship between years of publication.

Similarly, morality frame, $10(43.5 \%)$ was the most frequent in Hintset magazine during the second period. Human interest, 9 (18\%), and morality, $8(16 \%)$ were the first and second most frequent frame during the first period. Corruption, 7 (14\%), social work, $6(12 \%)$, and responsibility, $5(10 \%)$ were ranked third to fifth most frequent dominant frames in the period. However, the educative, 2 (4\%) frame was the second least frequent dominant frame in period 1. Conservative, $1(4.3 \%)$ and economic, $3(13 \%)$ conflict, 2 (8.7\%) and responsibility, 2 (8.7\%) frames were ranked second up to fourth most frequent frames in period 2 . The Pearson chi-square test result demonstrated that (chisquare $=27.406, p=0.000$, and $p<0.05$ ). This showed that the Hamer magazine moral development story actors had a relationship between years of publication. The Pearson chi-square test result demonstrated that (chi-square $=66.130, p=0.000$, and $p<0.05)$. This showed that the Hintset magazine moral development story frames had a relationship between years of publication.

Do peace development stories, or, sources, or, story actors, or dominant frames have a relationship with years of publication in Hamer and, (or) Hintset magazines?. Peace development stories were the third most covered stories in both studied magazines. The result in Table 7 showed that 59 (16.4\%) of development stories were peace development stories in Hamer magazine. Among these, $29(49.2 \%)$ and 30 (50.8\%) were found in the first and second periods consecutively. The Pearson chi-square test result demonstrated that (chi-square $=0.197, p=0.671$, and 


\begin{tabular}{|c|c|c|c|c|c|c|c|c|c|c|c|c|c|}
\hline \multicolumn{2}{|l|}{ Variables } & \multicolumn{4}{|c|}{ Hamer } & \multicolumn{4}{|c|}{ Hintset } & \multicolumn{2}{|c|}{ Chi-square } & \multicolumn{2}{|l|}{$p$-value } \\
\hline \multicolumn{2}{|c|}{ Years of publication (categorical) } & \multicolumn{2}{|c|}{ 1993-2005 } & \multicolumn{2}{|c|}{ 2007-2021 } & \multicolumn{2}{|c|}{ 2014-2017 } & \multicolumn{2}{|c|}{ 2018-2021 } & $\begin{array}{r}\text { Hamer } \\
0.197\end{array}$ & $\frac{\text { Hintset }}{3.956}$ & $\begin{array}{l}\text { Hamer } \\
0.671\end{array}$ & $\frac{\text { Hintset }}{0.059}$ \\
\hline \multirow[t]{6}{*}{ Sources of the story } & Sacred & 1 & 8.3 & 11 & 91.7 & 4 & 44.4 & 5 & 55.6 & 29.009 & 6.281 & 0.000 & 0.392 \\
\hline & Media & - & - & 9 & 100 & 14 & 82.4 & 3 & 17.6 & & & & \\
\hline & Celebrities & - & - & 2 & 100 & 3 & 75 & 1 & 25 & & & & \\
\hline & Adherents & 16 & & 7 & & 18 & 94.7 & 1 & 5.3 & & & & \\
\hline & ROs & 9 & 90 & 1 & 10 & 14 & 93.3 & 1 & 6.7 & & & & \\
\hline & GOs & 3 & 100 & - & - & 1 & 100 & - & - & & & & \\
\hline Story actors & Celebrities & 7 & 70 & 3 & 30 & 1 & 100 & - & - & & & & \\
\hline \multirow[t]{10}{*}{ Dominant frames } & Morality & 4 & 30.8 & 9 & 69.2 & 10 & 90.9 & 1 & 9.1 & 102.584 & 81.457 & 0.000 & 0.000 \\
\hline & Conflict & 13 & 65 & 7 & 35 & 20 & 95.2 & 1 & 4.8 & & & & \\
\hline & Economic & - & - & 2 & 100 & - & - & - & - & & & & \\
\hline & Educative & - & - & 1 & 100 & - & - & - & - & & & & \\
\hline & Conservative & - & - & - & - & 2 & 100 & - & - & & & & \\
\hline & Political power & - & - & - & & 1 & 100 & - & - & & & & \\
\hline & Exclusivist & 3 & 42.9 & 4 & 57.1 & 10 & 100 & - & - & & & & \\
\hline & Corruption & - & - & 1 & 100 & 4 & 80 & 1 & 20 & & & & \\
\hline & Responsibility & 2 & 66.7 & 1 & 33.3 & 4 & 44.4 & 5 & 55.6 & & & & \\
\hline & Human interest & 7 & 58.3 & 5 & 41.7 & 3 & 50 & 3 & 50 & & & & \\
\hline
\end{tabular}

$p>0.05)$. This showed that the Hamer magazine peace development stories did not have a relationship between years of publication.

The result in Table 7 revealed that adherents, 16 (55.2\%), religious organizations, $9(31 \%)$ and government organizations, 3 $(10.3 \%)$ were ranked first up to third most frequent peace development story sources in the first period. Sacred, 11 (36.7\%) was the most frequent peace development source during the second period. Media, 9 (30\%) and adherents, 7 (23.3\%) were the second and third frequent peace development story actors in period 2. On the contrary, religious organizations, 1 (3.3\%), and celebrities, 2 (6.5\%) were the least and second least frequent peace development sources during the second period. The Pearson chisquare test result demonstrated that (chi-square $=29.009$, $p=0.000$, and $p<0.05$ ). This showed that the Hamer magazine peace development story sources had a relationship between years of publication. Similar to Hamer magazine, Hintset magazine covered $65(19.9 \%)$ peace development stories. Of these, 54 $(83.1 \%)$ were found in period 1 whereas $11(16.9 \%)$ of them were found in the second period. The Pearson chi-square test result demonstrated that (chi-square $=3.956, p=0.059$, and $p>0.05$ ). This showed that the Hintest magazine peace development stories did not have a relationship between years of publication.

As can be seen from the above table, adherents, 18 (33.3\%), media, $14(25.9 \%)$ and religious organizations, 14 (25.9\%) were the first and second most frequent peace development sources in Hintset magazine during the first period. However, government organizations, 1 (1.9\%), celebrities, 3 (5.6\%), and sacred, 4 (7.4\%) were ranked from first up to third least frequent peace development story sources. During the second period, conversely, sacred, 5 (45.5\%) and media, 3 (27.3\%) were the most and second most frequently found peace development story sources. On the other hand, celebrities, 1 (9.1\%), adherents, 1 (9.1\%), and religious organizations, $1(9.1 \%)$ were the least frequent peace development story sources of the period. The Pearson chi-square test result demonstrated that (chi-square $=6.281, p=0.392$, and $p>0.05$ ). This showed that the Hintset magazine peace development story sources did not have a relationship between years of publication.

There were about six peace development story actors in both studied magazines. Adherents, 8 (27.6\%), and protestant leaders, $8(27.6 \%)$ were the most frequent peace development actors during the first period in Hamer magazine. Celebrities, 7 (24.1\%) and political leaders, $4(13.8 \%)$ were the second and third most frequent peace development actors in the same period. However, prophets, 1 (3.4\%) and EOTC leaders, 1 (3.4\%) were the scarcest peace development, actors. As indicated in the above table, adherents, $16(53.3 \%)$ and protestant leaders, 7 (23.3\%) were the first and second frequent peace development actors during the second period. EOTC leaders, $3(10 \%)$ and celebrities, $3(10 \%)$ were the second least frequent peace development actors in period 2 . Similarly, prophets, $1(3.3 \%)$ were the scarcest peace development actors during the second period in Hamer magazine. The Pearson chi-square test result demonstrated that (chi-square $=85.118, p=0.000$, and $p<0.05$ ). The Chi-square result has also solidified the identified trend, with a $p$-value lower than the conventional significance level. This showed that the Hamer magazine peace development story actors had a relationship between years of publication.

In Hintset magazine also the most and second most frequent peace development actors were adherents, $12(22.2 \%)$ and protestant leaders, $18(33.3 \%)$ during the first period. Prophets, $7(13 \%)$ and political leaders, $4(7.4 \%)$ were the third and fourth most frequent peace development actors. On the other hand, celebrities, 1 (1.9\%) and EOTC leaders, 2 (3.7\%) were the least and second least frequent peace development actors during the first period. As it can be seen from Table 7, prophets, 5 (45.5\%) were the most frequent peace development actors during the 
second period in Hintset magazine. On the contrary, adherents, 3 (27.3\%) and protestant leaders, $3(27.3 \%)$ were the scarcest peace development actors in the second period. The Pearson chi-square test result demonstrated that (chi-square $=6.391, p=0.270$, and $p>0.05)$. This showed that the Hintset magazine peace development story actors did not relationship between years of publication. Regarding dominant frames, conflict, 13 (44.8\%) was the most frequent frame in Hamer magazine during the first period. Human interest, 7 (24.1\%) and morality, 4 (13.8\%) frames were the second and third frequent peace development frames in period 1 . On the other hand, responsibility, 2 (6.9\%) and exclusivist, 3 (10.3\%) frames were the least and second least frequent peace development frames during the first period. Likewise, in the second period, responsibility, 1(3.3\%), corruption, $1(3.3 \%)$, and educative, $1(3.3 \%)$ frame were the least frequent peace development frames. Morality, 9 (30\%), conflict, 7 (23.3\%), human interest, 5 (16.7\%), and exclusivist, $4(13.3 \%)$ were the most frequent frames consecutively whereas economic, 2 (6.7\%) frame was second least during the second period in Hamer magazine. The Pearson chi-square test result demonstrated that (chi-square $=109.116, p=0.000$, and $p<0.05$ ). This showed that the Hamer magazine peace development story frames had a relationship between years of publication.

Moreover, in Hintset magazine, conflict, 20 (37\%) frame was the most frequent one during the first period. Exclusivist, 10 (18.5\%) and morality, $10(18.5 \%)$ were the second most frequent during the first period. Corruption, 4 (7.4\%) and responsibility, 4 (7.4\%) were also the third most frequent peace development story frame. However, political power, 1 (1.9\%), conservative, 2 (3.7\%), and human interest, 3 (5.6\%) were ranked from least up to third least frequent dominant frames during the first period. In the second period, responsibility, 5 (45.5\%), and human interest, 3 (27.3\%) frames were most and second most frequent frames in Hintset magazine. Others, like corruption, 1 (9.1\%), conflict, 1 (9.1\%), and morality, 1 (9.1\%) frame were the least frequent ones. The Pearson chi-square test result demonstrated that (chisquare $=81.457, p=0.000$, and $p<0.05$ ). This showed that the Hintset magazine peace development story frames had a relationship between years of publication.

Do natural resource development stories, or, sources, or, story actors, or dominant frames have a relationship with years of publication in Hamer and, (or) Hintset magazines?. The finding in Table 8 exhibited that natural resource development stories were the least frequently found stories in both studied magazines and periods. A total of only $5(0.7 \%)$ stories were found in both magazines. Four $(0.6 \%)$ of them were found in Hamer magazine, and the remaining $1(0.1 \%)$ were from Hintset magazine. Natural resource development stories did not have a relationship between years of publication in both magazines since the Pearson chisquare test showed that (chi-square $=0.20, p=1$, and $p>0.05$ ) in Hamer magazine, and (chi-square $=0.365, p=1$, and $p>0.05$ ) in Hintset magazine. The above table showed that sacred, 2 (100\%) in the first period, and sacred, 1 (50\%), and media 1 (50\%) were sources of natural resource development stories in Hamer magazine. The Pearson chi-square test revealed that (chisquare $=4.919, p=0.670$, and $p>0.05)$. On the other hand, NGO, $1(100 \%)$ was the only natural resource development story source in Hintest magazine during the first period as the second period was left empty. The Pearson chi-square test disclosed that (chi-square $=162, p=0.000$, and $p<0.05$ ). The Chi-square result has also solidified the identified trend, with a $p$-value lower than the conventional significance level.

Adherents were the only natural resource development actors in both magazines. In Hamer magazine, adherents, 2 (50\%) each were found in both periods. The Pearson chi-square test result divulged that (chi-square $=4.919, p=0.670$, and $p>0.05$ ). Therefore, in Hamer magazine, natural resource development story actors did not have a relationship with years of publication. Similarly, in Hintset magazine, 1 (100\%) of natural resource development story actor was adherents. The Pearson chi-square test result unveiled that (chi-square $=162.4, p=0.000$, and $p<0.05)$. Hence, in Hintset magazine, natural resource development story actors had a relationship with years of publication.

Regarding dominant frames, corruption and responsibility frames were found in Hamer magazine. During the first period, 2 $(100 \%)$ of frames were corruption frames whereas, in the second period, corruption, 1 (50\%) and responsibility, 1 (50\%) frames were exhibited. The Pearson chi-square test result unveiled that (chi-square $=134.070, p=0.000$, and $p<0.05$ ). Hence, in Hamer magazine, natural resource development story frames had a relationship with years of publication. In Hintset magazine, however, social work, $1(100 \%)$ was the only frame in the first period. The Pearson chi-square test result unveiled that (chisquare $=13.861, p=0.179$, and $p>0.05)$. It indicated that in Hintset magazine, natural resource development story frames did not have a relationship with years of publication.

\section{Discussion}

The above findings from the content analysis provided necessary prerequisites for supporting previous studies that Agenda-setting theory asserts the existence of a serious link between the prominence given to topics in a communicator's messages and their perceived importance within the reputation. As the literature review has shown, the role of sources is key to the agenda-setting process because of their ability to set the agenda by being the right "who." Topics emphasized within the mass media or other channels are viewed as being more important than those not covered (McCombs and Shaw, 1993). Hence, the result depicted that social development stories were the most prominent issues in the studied magazines.

Similarly, education and morality frames were the most dominant of them as religious media (Hamer and Hintset) were playing the moral conscience of the society. Each society might define development in its terms to reflect its underlying culture, assumption, values, and goals (Dahl, 1996). Hence, the studied magazines put development from economic, social, political, cultural, moral, and peace perspective. For instance, the studied religious magazine, Hamer and Hintset, have significantly covered social development issues like education, health, marriage, and demography as every social organization must have agendas to prioritize their concerns and make decisions on where to take a position (Dearing et al., 1996).

In numerous developing countries, power is now fundamentally fragmented, often finding its main expression in social networks, including those expressing various religious ideas through their media. As indicated by (Gensicke, 2001) modernization made a decent move of managing esteems in the course of an improvement of human presence within the present world instead of within beyond the world. Similarly, the studied magazine covered social and peace development themes significantly. Similarly, throughout the developing world, various religious entities own land, provide services such as healthcare and education, livelihood, orphans and disabled people by farmers, fisherfolk, and slum dwellers (Olsson and Wohlgemuth, 2003). Likewise, the finding revealed that a great number of development issues were covered. For instance, monasteries harvested fruits and vegetables; clerical schools contributed a lot to the nation's development; EOTC forests can contribute to carbon trade, etc. Hintset narrated how to lend in hand Orphans, HIV/AIDS victims, etc. 


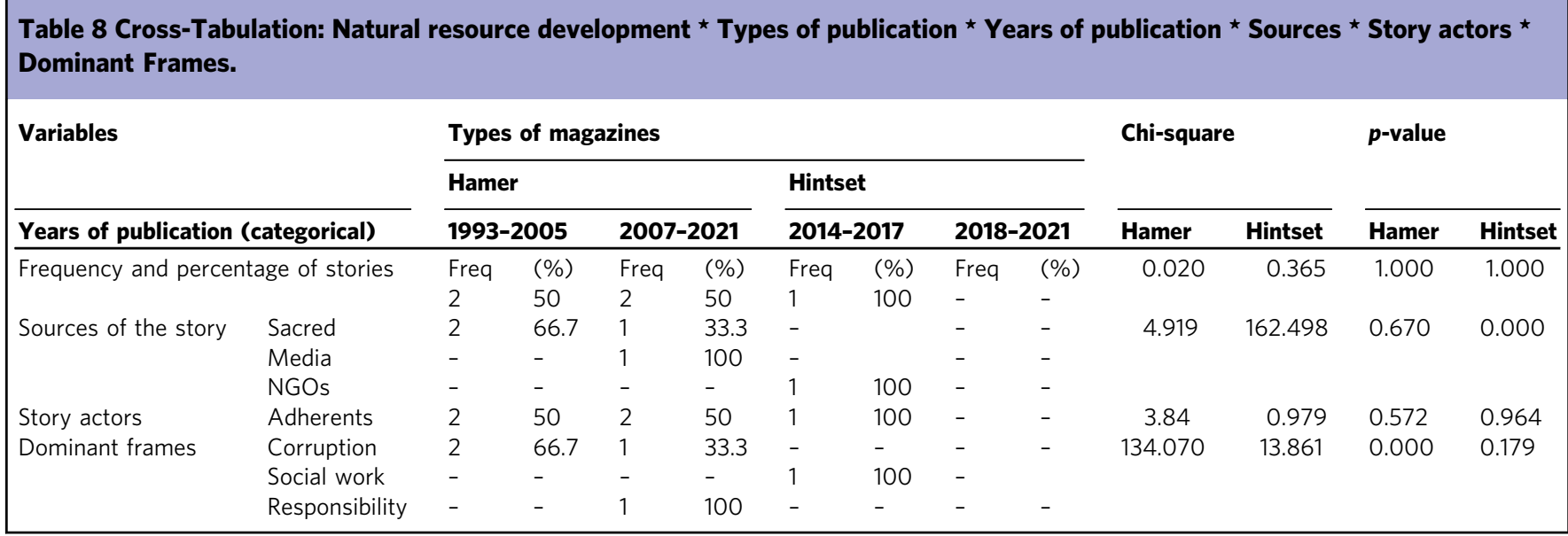

Various religious traditions create obedience or norms in economic activities is one primary way for adherents to acknowledge and demonstrate faith (Malloch, 2003). The dependency world view is established in a socio-economy and political point of view (Servaes and Malikhao, 2008). However, the finding revealed that political and economic development themes were scarcely used themes.

The state and all other sections of civil society must engender a new paradigm of values, which will ensure an ethos of greater sharing and cooperation (Kurien, 1996). Similarly, the finding indicated a great number of moral development issues were found. Sharing resources, ideas, values, and thoughts were the most frequent frames. However, efforts of modernization were necessarily doomed to failure since the approach was to discard but not to fertilize domestic cultures (Asgedom, 2000). The mass media are also agents of social change in the service of national development (So, 1990). The change in behavior expected after interacting with media should include changes in attitudes, beliefs, skills, and social norms (Moyer-Gusé, 2008).

Religion plays a central, integrating role in social and cultural life in most developing countries as there are many more religious leaders than health workers (UNICEF, 1995). Religious leaders are also in closer and regular contact with all age groups in society, and their voice is highly respected. Similarly, religious media are more trusted than secular media by adherents as religious leaders' voices are heard and respected. In conventional communities, strict pioneers are regularly more powerful than nearby government authorities or mainstream community leaders (UNICEF, 1995).

Christian churches in providing educational services in, for example, the Democratic Republic of Congo, where for years Christian schools have played a definitive role in educational provision (Ellis and Ter Haar, 2004). In the same vein, Negash (1996) stated that the greatest shortcomings of the education system in Africa and Ethiopia, in particular, is that it is poorly related to and interlinked with the traditions of education, which predate the coming of modern education. One of the major criteria to evaluate mass media output is the extent of its influence on society, or its educational value (Nigussie, 2006). Similarly, the study confirmed that the educative frame was the most frequently found theme.

Previous studies indicated that Christian Churches have pronounced a factor that inhibits the process of modernization; and of the three Christian Churches most popular in the countries belonging to the European culture, the Protestant Church was recognized as one that supports the cause of modernization the most, while the Orthodox Church was the one that supported it least.

Arnoldov (1988) has said that people do not realize their moral and spiritual resources as the creator of both culture and society.
They rather believe which wisdom of the ages, the experience of their life, wealth, and impulse toward the future. Culture is inconceivable without humans, and human's life is inconceivable without it (Arnoldov, 1988). Similarly, Iwe (1992) has said that people express a marked degree of consciousness of their cultural norms and the ability to differentiate them from individual habits.

In earlier societies, social institutions like family, school, and church were the most important providers of information, tradition, and moral orientation for the individual member of society. Today, these institutions have lost some of their previous authority, and the media have taken over their role as providers of moral orientation, and they have become society's most influential narrator about society itself (Hjarvard, 2013). It is therefore a shift from unmediated history to mediated history (Livingstone, 2009), which places media and media analysis at the center of current developments.

Without adequate resources, explicit preparation, and commitment over time, peace will remain a distant ideal rather than a practical goal. However, the result depicted that Hintset magazine blamed intra religious preaching instead of negotiating. Hamer also repeatedly propagates inter-religion relations negatively. Thus, the media portrayal of sustainability as a means of achieving a rediscovered delight bears significant representations that cover all aspects of human life and environment, such as for people, planet, and prosperity of transforming our World in the 2030 Agenda for Sustainable Development, (Bexell, and Jönsson, 2017).

Even though coverage of climate change in non-industrialized countries is increasing, the quantity and quality of reporting do not match the scale of the problem (Anderson, 2010). Similarly, the religious magazines covered natural resource management scarcely. Ethiopia suffers from a lack of information to adapt and mitigate climate change issues. Ethiopian farmers do not receive satisfactory information to adapt to climate change.

It is known that media have the power to influence public opinion as well as social policy about significant social matters. The media's attention on climate change awareness is thus obligatory, and how it is framed has implications for both public perception and policymaking (Shanahan, 2009).

Improvement is being observed from time to time in media coverage of climate change, but it doesn't get much attention in terms of quality, (Shanahan, 2009). Media usually give higher coverage for other issues than climate change. Despite an increase in coverage, climate change is still not an easy subject area for non-specialist media to get to grips with.

These media representations of sustainability are mainly related to the three classic dimensions of the concept. More precisely, they give meaning to sustainability in the spheres of economic, environmental, and social predictions through media discourse. 
Hence, socially responsible investments devote their funds to companies of an ethical, social, or environmental nature.

The fact that this growth is consistent with a constant increase in the volume of information on sustainability is proof the volume of media coverage can generally indicate that an issue is awarded over time in a given context. Hence, measuring media salience by the volume or frequency of media coverage has emerged as a relatively common method in agenda-setting research (Howlett, 1997). This growth can be, at the same time, the indicator of unconscious recognition of the ontological need of the human being to have a spiritual reference even if it declines any religious attachment. In this perspective, sustainability presents to consciousness not as a need to be satisfied in the different areas of human activity, but as the daily experience of a moral experience imposed and ritualized by a secular trans-ideological spirituality (Camus and Poulain, 2008; Champion, 2000).

According to Melkote and Steeves (2001), the alternative development world view puts an accentuation on diminishing disparities and on improving the state of the least fortunate of the poor by meeting their fundamental needs. Participation has been key. Hence, this research finding showed that adherents that represent grassroots participants were the most frequent sources and story actors of development stories in the studied magazines as compared to religious leaders, media, celebrities, and religious and government organizations.

\section{Conclusion}

The outcomes of the research are presented in three conclusive remarks. First, the content analysis of the study focused on identifying the depictions of development issues through quantitative content analysis. As a result, it was observed that the major differences of the representations were diverse in combinations of variables, but evident. Essentially, the two religious magazines portrayed the development stories differently in terms of the selections of sources, story actors, and dominant frames. The mass media are also agents of social change in the service of national development (So, 1990). The change in behavior expected after interacting with media should include changes in attitudes, beliefs, skills, and social norms (Moyer-Gusé, 2008). The result supported that social and moral development issues were the most frequently covered development stories in both magazines.

Second, the cross-tabulations of such dispositions quantitatively contributed to supporting previous studies undertaking the religious media coverage of development issues. The research mainly argued that within the coverage of development articles in Hamer and Hintset, the sources, story actors, and dominant frames are explicitly represented. The study has given all publication periods; the analytic scope of the research was exhaustive, as $(n=685)$. Therefore, the study has examined the identified types of development representation that are persistent over time, as Collins (2004) suggests that rituals of solidarity after conflict gradually change after a certain period.

Third, specific outcomes indicated that adherents and sacred were the dominant development sources in both magazines. Specifically, adherents, sacred and religious organizations were the dominant economic development story sources in Hamer magazine; on the contrary, adherents and media were the most frequent sources of economic development issues in Hintset magazine. Regarding social development story sources, sacred books were the most frequently taken sources in both studied magazines. Adherents and sacred were the sources of political development stories in Hamer magazine. However, media were the most frequent sources in Hintset magazine. Regarding cultural development story sources, adherents and religious organizations were dominant sources in Hamer magazine whereas, in Hintset magazine, Sacred, and media were the dominant sources. Religious organizations and media were the most frequent historical development sources in Hamer magazine. Most of the moral development sources were sacred books in Hamer magazine.

Economic development and social work frames were the most dominant economic development issue frames in both magazines. Furthermore, the responsibility frame was also dominant in Hintset magazine, but the human-interest frame was frequently found in Hamer magazine. The educative frame was the most dominant in social development issues in both studied magazine periods. Responsibility frame was the dominant political and cultural development issue in Hamer, and political and conservative frames were the dominant political and cultural development issues in Hintset magazine, consecutively. Responsibility and human-interest frames were the most frequent historical development issues in Hamer and Hintset magazines. The morality frame was the most dominant in moral development issues in both magazines. The conflict frame was the most dominant peace development issue frame in both magazines. Corruption and responsibility frames were the most dominant natural resource development issue frames in Hamer and Hintset magazines, respectively.

The finding depicted that there were no single development paradigms that have been found. Like modernization, top-down communication practice from religious leaders has been found. Similar to the dependency paradigm, context-based development communication was employed; and then, alternative development, which gives grassroots communication practice, adherents, and local communities, were active participants in the source and story actors of development stories.

In addition, although the methodological strategy here offered an insightful discovery of the comparative patterns of representation between EOTC and EEC, it was unmanageable for the researcher to examine the site of production and the site of the audience for the identified manners. For these reasons, the obtained findings invite for research that can further validate the conclusion and provide reinforcement to the outlined shortcomings. A possible contribution in this regard could be, for instance, to conduct research covering a variety of religious media (more than two) and proceed qualitative interviews to examine whether, on the one hand, the above-identified patterns and the underlying discourse of representations have on multicultural-political intentions on the site of production. In addition, on the other hand, the researcher hopes that through a more qualitative and in-depth examination of the audience effect, the expected research could finalize the circulatory links between the site of production, and the audience.

\section{Data availability}

All data analyzed are contained in the paper.

Received: 15 December 2020; Accepted: 24 January 2022; Published online: 10 February 2022

\section{Note}

1 Ethiopian authors are referenced by their first names instead of surnames, as first names come before surnames in Ethiopia.

\section{References}

Amanuel A (2004) Development journalism to promote good governance: The Ethiopian Press Practice. Print Media Journal No. 4 Ethiopian Press Agency, Addis Ababa

Anderson A (2010) Combating climate change through quality education Brookings Global Economy and Development, Washington, DC

Arnoldov AL (1988) Man in the World of Culture. In: Kulikova IS, Mshvenieradze VV (eds.) The philosophical conception of man. Progress, Moscow

Asgedom A (2000) The state of educational research in Ethiopia. Ethiop J Educ 20(2):19-47 
Bateson GA (1972) A theory of play and fantasy. In GA Bateson (ed.). Steps to an ecology of mind. New York: Chandler

Bexell M, Jönsson K (2017) Responsibility and the United Nations' sustainable development goals. In: Forum for development studies. vol. 44, No. 1. Routledge. pp. 13-29

Bryman A (2006) Integrating quantitative and qualitative research: how is it done? Qual Res 6(1):97-113

Burkey S (1993) People first: A guide to self-reliant participatory rural development. Zed Books Ltd

Camus S, Poulain M (2008) La spiritualité: Émergence d'une tendance dans la consommation. Manag Avenir 5:72-90

Chala G (2012) A comparative study of the coverage of development issues in the Ethiopian herald and the reporter. Addis Ababa University, Addis Ababa, Ethiopia

Champion F (2000) Thérapies et nouvelles spiritualités. Sci Hum 106:32-35

Collins R (2004) Rituals of solidarity and security in the wake of a terrorist attack. Sociol Theory 22(1):53-87

Dahl AL (1996) Spiritual dimensions of sustainable development. In Bucharest, Romania, a paper was presented at a Workshop on Sustainable Development and International Cooperation

Dearing JW, Rogers EM, Rogers E (1996) Agenda-setting (Vol. 6): Sage.

Ellis S, Ter Haar G (2004) Worlds of power: Religious thought and political practice in Africa (Vol. 1). Oxford University Press on Demand

Fisher J (2011) The four domains model: Connecting spirituality, health and wellbeing. Religions 2(1):17-28

Gensicke T (2001) Das bürgerschaftliche Engagement der Deutschen-Image, Intensität und Bereiche. In: Bürgerengagement in Deutschland. VS Verlag für Sozialwissenschaften, Wiesbaden. pp. 283-304

Gitlin T (1980) The whole world is watching: Mass media in the making and unmaking of the new left. Berkeley: University of California Press

Goffman E (1974) Frame analysis: an essay on the organization of experience. New York: Harper and Row

Gumucio-Dagron A (2001) Making waves: participatory communication for social change: a report to the rockefeller foundation. Rockefeller Foundation

Hjarvard S (2013) The mediatization of culture and society: Routledge

Holsti OR (1969) Content analysis for the social sciences and humanities. AddisonWesley, Reading. MA

Howlett M (1997) Issue-attention and punctuated equilibria models reconsidered: an empirical examination of the dynamics of agenda-setting in Canada. Can J Polit Sci 30(1):3-29

International Programme for the Development of Communication (2008) Media development indicators: a framework for assessing media development. UNESCO, France, Paris

Iwe NSS (1992) Religion, morality and ethics. A paper presented at the professors world peace academy conference

Jensen KB (2013) A handbook of media and communication research: Qualitative and quantitative methodologies. Routledge, London

Kurien J (1996) Towards a new agenda for sustainable small-scale fisheries development. South Indian Federation of Fishermen Societies, Thiruvananthapuram, 48-pp

Livingstone S (2009) On the mediation of everything: ICA presidential address 2008. J Commun 59(1):1-18

Malloch TR (2003) Social, human and spiritual capital in economic development. Retrieved April 24:2005

McCombs ME, Shaw DL (1972) The agenda-setting function of mass media. Public Opin Quart 36(2):176-187

McCombs ME, Shaw DL (1993) The evolution of agenda-setting research: twentyfive years in the marketplace of ideas. J Commun 43(2):58-67

McCombs ME, Shaw DL, Weaver DH (2014) New directions in agenda-setting theory and research. Mass Commun Soc 17(6):781-802

Mefalopulos P (2008) Development communication sourcebook: Broadening the boundaries of communication. The World Bank

Melkote SR, Steeves HL (2001) Communication for development in the Third World: Theory and practice for empowerment. Sage

Moges M (2007) Exploratory study on the coverage of rural development news on ethiopian radio: case Study of 8 PM (Evening) News. Addis Ababa University

Moyer-Gusé E (2008) Toward a theory of entertainment persuasion: Explaining the persuasive effects of entertainment-education messages. Commun Theor 18(3):407-425

Narula R, Duysters G (2004) Globalization and trends in international R\&D alliances. J Int Manag 10(2):199-218

Negash T (1996) Rethinking education in Ethiopia. Nordiska Afrikainstitutet

Nigussie T (2006) Ethiopian Mass Media Profile: Population Media Centre. Addis Ababa

Norris P, Inglehart R (2014) Sacré versus Secularization. Religion et Politique dans le Monde. Editions de l'Université de Bruxelles, Bruxelles

Olsson J, Wohlgemuth L (eds) (2003) Dialogue in pursuit of development. Almqvist \& Wiksell
Pickel G (2012) Religiosity and bonding to the church in East Germany in eastern european comparison: is East Germany still following a special path? In: Pickel G, Sammet K eds. Transformations of Religiosity. Religion and Religiosity in Eastern Europe 1989-2010. VS-Verlag, Wiesbaden, pp. 135-154

Rashi T, McCombs M (2015) Agenda setting, religion and new media: The Chabad case study. J Relig Media Digit Cult 4(1):126-145

Rogers EM, Dearing JW, Bregman D (1993) The anatomy of agenda-setting research. J Commun 43(2):68-84

Sádaba-Garraza MT (2001) Origen, aplicación y límites de la 'teoría del encuadre' (framing) en comunicación. Comunicación y Sociedad, 24(2):143-175

Sahgal N, Smith G (2009) A religious portrait of African-Americans, Pew Research Center's Forum on Religion and Public Life. Washington, DC

Sarantakos S (2005) Social research. Palgrave Macmillan, New York, NY

Servaes J (1999) Communication for development. One world, multiple cultures. Hampton Press, Cresskill

Servaes J, Malikhao P (2008) Development communication approaches in an international perspective. In: Communication for development and social change. Sage. p. 158

Shanahan M (2009) Climate change and the media: media coverage of climate change in non-industrialized countries. Peter Lang Publishing, London, pp. 145-157

Singhal A, Rogers EM (2001) India's communication revolution : from bullock carts to cyber marts. New Dehli; Thousand Oaks, Calif.: Sage

So AY (1990) Social change and development: Modernization, dependency and world-system theories. Sage

Todaro M, Smith S (2009) Urbanization and rural-urban migration: theory and policy (eds.). In: Economic development. In: Addison-Wesley Series, New York

Tuchman G (1978) Making news: A study in the construction of reality

UNICEF (1995) Religious leaders as health communicators. UNICEF, quoted in Haynes, J. (2007), Religion and Development: Conflict or Cooperation, New York, NY

Vilanilam JV (2005) Mass communication in India: A sociological perspective. Sage Watson J (2008) Media communication: An introduction to theory and process. Macmillan International Higher Education

Weber M (2009) The theory of social and economic organization. Simon and Schuster

Xiaoge X (2009) Measuring and mapping development journalism. International Communication Association, 1-22

Zhou S, Kim Y, Luo Y, Qiao F (2016) Is the agenda set? State of agenda-setting research in China and Korea. Asian. J Commun 26(6):566-582

\section{Competing interests}

The authors declare no competing interests.

\section{Ethical approval}

The authors confirm that all research was performed by the Declaration of Helsinki.

\section{Informed consent}

This article does not contain any studies with human participants performed by any of the authors.

\section{Additional information}

Correspondence and requests for materials should be addressed to Negesse Gessese.

Reprints and permission information is available at http://www.nature.com/reprint

Publisher's note Springer Nature remains neutral with regard to jurisdictional claims in published maps and institutional affiliations.

Open Access This article is licensed under a Creative Commons Attribution 4.0 International License, which permits use, sharing, adaptation, distribution and reproduction in any medium or format, as long as you give appropriate credit to the original author(s) and the source, provide a link to the Creative Commons license, and indicate if changes were made. The images or other third party material in this article are included in the article's Creative Commons license, unless indicated otherwise in a credit line to the material. If material is not included in the article's Creative Commons license and your intended use is not permitted by statutory regulation or exceeds the permitted use, you will need to obtain permission directly from the copyright holder. To view a copy of this license, visit http://creativecommons.org/ licenses/by/4.0/

(c) The Author(s) 2022 